\title{
Plant Byproducts as Part of Edible Coatings: A Case Study with Parsley, Grape and Blueberry Pomace
}

\author{
Alexandra Tauferova ${ }^{1}\left(\mathbb{D}\right.$, Matej Pospiech $^{1}$, Zdenka Javurkova $^{1}\left(\mathbb{D}\right.$, Bohuslava Tremlova $^{1, *} \mathbb{C}^{\circ}$, Dani Dordevic ${ }^{1}(\mathbb{D}$, \\ Simona Jancikova ${ }^{1}{ }^{1}$, Karolina Tesikova ${ }^{1}$, Michal Zdarsky ${ }^{1}$, Tomas Vitez ${ }^{2,3}{ }^{(1)}$ and Monika Vitezova ${ }^{2}(\mathbb{C}$ \\ 1 Department of Plant Origin Food Sciences, Faculty of Veterinary Hygiene and Ecology, University of \\ Veterinary Sciences Brno, Palackeho tr. 1946/1, 61242 Brno, Czech Republic; tauferovaa@vfu.cz (A.T.); \\ pospiechm@vfu.cz (M.P.); javurkovaz@vfu.cz (Z.J.); dordevicd@vfu.cz (D.D.); jancikovas@vfu.cz (S.J.); \\ tesikovak@vfu.cz (K.T.); zdarskym@vfu.cz (M.Z.) \\ 2 Department of Experimental Biology, Faculty of Science, Masaryk University, Kamenice 5, \\ 62500 Brno, Czech Republic; tomas.vitez@mendelu.cz (T.V.); vitezova@sci.muni.cz (M.V.) \\ 3 Department of Agricultural, Food and Environmental Engineering, Faculty of AgriSciences, \\ Mendel University in Brno, Zemedelska 1, 61300 Brno, Czech Republic \\ * Correspondence: tremlovab@vfu.cz
}

check for updates

Citation: Tauferova, A.; Pospiech, M.; Javurkova, Z.; Tremlova, B.; Dordevic, D.; Jancikova, S.; Tesikova, K.; Zdarsky, M.; Vitez, T.; Vitezova, M Plant Byproducts as Part of Edible Coatings: A Case Study with Parsley, Grape and Blueberry Pomace. Polymers 2021, 13, 2578. https:// doi.org/10.3390/polym13152578

Academic Editor: T M Indra Mahlia

Received: 16 July 2021

Accepted: 27 July 2021

Published: 3 August 2021

Publisher's Note: MDPI stays neutra with regard to jurisdictional claims in published maps and institutional affiliations.

Copyright: (c) 2021 by the authors. Licensee MDPI, Basel, Switzerland. This article is an open access article distributed under the terms and conditions of the Creative Commons Attribution (CC BY) license (https:// creativecommons.org/licenses/by/ $4.0 /)$.

\begin{abstract}
Studies dealing with the development of edible/biodegradable packaging have been gaining popularity since these commodities are marked as being ecofriendly, especially when byproducts are incorporated. Consequently, this study aimed at the development of chitosan-based coatings with plant byproducts. Their sensory properties, colour attributes, occurrence of cracks in microstructure and biodegradability were analysed. Coatings containing grape and blueberry pomace had statistically significantly $(p<0.05)$ higher levels of colour intensity. Coating samples were characterised by lower aroma intensity (3.46-4.77), relatively smooth surface (2.40-5.86), and low stickiness (2.11-3.14). In the overall hedonic evaluation, the samples containing parsley pomace in all concentrations and a sample containing $5 \%$ grape pomace achieved a statistically significantly $(p<0.05)$ better evaluation (5.76-5.93). The lowest values of the parameter $\Delta \mathrm{E} 2000$ were recorded for the sample containing $5 \%$ parsley pomace (3.5); the highest was for the sample with $20 \%$ blueberry pomace (39.3). An analysis of the coating surface microstructure showed the presence of surface cracks at an $80 \mathrm{~K}$ magnification but the protective function of the edible coating was not disrupted by the added plant pomace. The produced samples can be considered to have a high biodegradability rate. The results of our experimentally produced coatings indicate their possible application on a commercial scale.
\end{abstract}

Keywords: biodegradability; sensory; scanning electron microscopy; CIELab; plant extracts

\section{Introduction}

Biodegradable edible coatings have been widely studied recently as they represent a sustainable and environmentally sound solution for primary packaging in the food industry. They can act as a barrier against microbial contamination, decrease the rate of oxidation, prevent or decrease the rate of moisture loss and other types of physical deterioration [1-3]. Barrier properties of edible coatings in the sense of physical coating integrity and cracks occurrence are often studied by means of scanning electron microscopy [4-6]. As they are in the closest contact with the food, their significant advantage is their ability to protect the food product in a non-toxic way. If antioxidant ingredients are included, they can further prolong the shelf life and enhance the nutritional value of a packaged food item by migrating such bioactive compounds from the coating [7,8]. Polyphenols are one of the main categories of commonly used bioactive agents [9-11]. Recent research studies showed new possibilities for how to isolate potent natural antioxidants or how to combine phenolic antioxidants with other functional ingredients to increase the efficiency of the manufacturing process in the food industry [12,13]. The use of bioactive compounds from 
various food industry byproducts is an effective strategy to decrease both the environmental impact and production costs [14,15].

Considering all these facts, an edible coating containing potent antioxidants derived from byproducts could be of great value for the food industry, as long as the particular coating is accepted by consumers with regard to its sensory properties. Therefore, it is essential to measure the acceptability of produced novel coatings for consumers. The attributes of the edible coating should not interfere with the sensory attributes of the food product [16].

Although there is still a gap between food packaging materials in the field of research and on the commercial scale, many biodegradable materials are being increasingly considered for food packaging production [17]. These include protein-, lipid- and polysaccharidebased coatings. To improve the natural properties of these polymers, additional functional ingredients or processing technologies, including nanotechnology among others, have been proposed [18]. In polysaccharide-based edible packaging materials, chitosan is one of numerous edible polymer options frequently used in the manufacturing of edible coatings $[5-7,9,11]$. Chitosan is the deacetylated form of chitin-the second most abundant polysaccharide in nature after cellulose [19]. The inclusion of chitosan has great potential as it shows high antimicrobial activity and compatibility with other biopolymers and active agents [20]. Table 1 shows a brief review of recently produced chitosan-based coatings, indicating the activities and the food matrix.

Chitosan based edible/biodegradable films showed significant potential in the food industry, extending the shelf life of postharvest fruits, such as in the work of Jiang et al. [21], where chitosan coatings (both low molecular weight and high molecular weight) postponed the storage period of blueberry fruits. The loss of antioxidant capacity is the reason for the shorter storage period. Guava fruits immersed in chitosan coatings showed a reduced loss of antioxidant capacity during storage (20 days of low temperature storage) [22]. Chitosan coatings also showed their effectiveness at room temperature in concentrations of up to $3 \%$. It was found that edible chitosan coatings prolonged the quality attributes of mango during storage at room temperature, affecting starch degradation rate and mitochondrial respiration [23]. There are also differences between coatings made from low, medium and high molecular weight chitosan. The study of Drevinskas et al. [24] showed that high molecular weight chitosan had a more highly positive influence on the shelf life of two kiwi cultivars (Sentiabrskaya and Anykšta cultivars) in comparison with VIR2 kiwi cultivar. Hard-green mangoes stored at room temperature and relative humidity of $60 \%$ to $70 \%$ during 2 weeks and immersed in the composite coating of chitosan (gallic acid:acetic acid) had lower decrease in acidity and vitamin $C$ content. The using of composite coating resulted in better flesh firmness than in untreated hard-green mangoes [25]. Chitosan solution $(1 \%)$ combined with spermidine $(0.1 \mathrm{ppm})$ showed antibacterial properties against Colletotrichum gloeosporioides on mango fruits; the solution of chitosan and spermidine also improved the firmness and deterioration processes were delayed [26]. Fresh cut apples represent a very vulnerable commodity with a short shelf life. Chitosan with carboxy methylcellulose sodium were used as a coating for fresh cut apples, positively affecting the weight loss, firmness, and browning [27]. Nanocrystals of cellulose in combination with chitosan positively affected (delayed ripening) pear during storage at ambient temperature and cold storage [28]. 
Table 1. A brief review of chitosan-based coatings applied on fruits.

\begin{tabular}{|c|c|c|c|}
\hline References & Chitosan & Food Matrix & Results \\
\hline [21] & 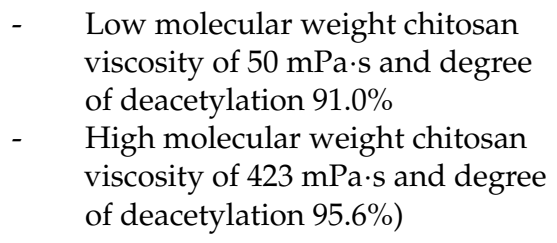 & $\begin{array}{l}\text { Blueberry (Vaccinium ashei } \\
\text { Reade) }\end{array}$ & $\begin{array}{l}\text { Chitosan coating to blueberry } \\
\text { positively effected the changes of } \\
\text { weight loss, firmness, total phenolics } \\
\text { and anthocyanins, same as storage } \\
\text { time increased. }\end{array}$ \\
\hline [22] & $\begin{array}{l}\text { Chitosan (low molecular weight, } \\
75 \% \text { deacetylated) }\end{array}$ & Guavas (cv Allahabad safeda) & $\begin{array}{l}\text { Samples coated with chitosan and } \\
\text { enriched with pomegranate peel extract } \\
\text { were effective in maintaining the } \\
\text { overall fruit quality. }\end{array}$ \\
\hline [23] & Chitosan (95-98\% deacetylated) & Mango (Mangifera indica L.) & $\begin{array}{l}\text { Chitosan delayed postharvest changes: } \\
\text { climacteric peak, water loss and } \\
\text { firmness. }\end{array}$ \\
\hline [25] & $\begin{array}{l}\text { - The composite of chitosan: gallic } \\
\text { acid: acetic acid (2:1:1) }\end{array}$ & $\begin{array}{c}\text { Hard-green } \\
\text { ‘Hindi-Besennara' mangoes }\end{array}$ & $\begin{array}{l}\text { The decay and weight loss of fruits } \\
\text { immersed in chitosan composite were } \\
\text { slowed. }\end{array}$ \\
\hline [26] & $\begin{array}{l}\text { - } \quad 1 \% \text { chitosan solution combined } \\
\text { with } 0.1 \mathrm{ppm} \text { spermidine }\end{array}$ & Mango (Mangifera indica L.) & $\begin{array}{l}\text { Inoculated mango fruit coated with } 1 \% \\
\text { chitosan and } 0.1 \text { ppm spermidine } \\
\text { showed the lowest fungal decay. }\end{array}$ \\
\hline$[24]$ & $\begin{array}{ll}\text { - } & \text { Low molecular weight chitosan } \\
\text { - } & \text { Medium molecular weight } \\
\text { chitosan } \\
\text { - } \quad \text { High molecular weight chitosan }\end{array}$ & Kiwi fruit (Actinidia kolomikta) & $\begin{array}{l}\text { High molecular weight chitosan had } \\
\text { better positive effect on the shelf life of } \\
\text { kiwi fruit cultivars. }\end{array}$ \\
\hline [27] & $\begin{array}{l}\text { - Chitosan (deacetylation } \\
\text { degree } \geq 85 \% \text { ) with carboxy } \\
\text { methylcellulose sodium } \\
\text { (viscosity: } 300-800 \text { mPa.s) }\end{array}$ & Fresh cut apples & $\begin{array}{l}\text { The coating positively affected weight } \\
\text { loss, firmness, and anti-browning. }\end{array}$ \\
\hline [28] & $\begin{array}{l}\text { - } \quad \text { Chitosan ( } 97 \% \text { degree of } \\
\text { deacetylation) reinforced by } \\
\text { cellulose nanocrystal }\end{array}$ & Pear fruit (Pyrus communis L.) & $\begin{array}{l}\text { Chitosan coating reinforced by } \\
\text { cellulose nanocrystal (5\%) postponed } \\
\text { chlorophyll degradation prevented } \\
\text { internal browning and retained } \\
\text { fruit firmness. }\end{array}$ \\
\hline
\end{tabular}

Blueberries have long been valued for their high levels of phenolic compounds and have the highest antioxidant capacity among traditional fruits and vegetables [29]. They contain high amounts of chlorogenic acid, which has been noted for its antioxidant properties and numerous flavonols, whose profiles differ between individual cultivars [30]. Grapes contain high amounts of phenols, flavonoids and anthocyanins with high antioxidant potential [31]. Anthocyanins are the characteristic pigments of grape berries and malvidin derivatives are the most abundant components, accounting for more than $68 \%$ of total anthocyanins in table grapes. Grape pomace is a high-quality biodegradable residue of the wine industry with a high potential to be used for further antioxidant extraction as substantial quantities of antioxidants remain in grape seeds, skins and stalks $[32,33]$. Parsley is a medicinal plant with various proven pharmacological properties including antioxidant, antibacterial and antifungal activities. Phenolic compounds, particularly flavonoids (such as apigenin-7-apiosylglucoside (apiin) and isorhamnetin-3-O-hexoside) are dominant compounds of parsley [34]. Other active compounds of parsley are essential oil components (especially myristicin and apiol), coumarins and furocoumarins [35].

In light of the above-mentioned information, the goal of this study was to develop bioactive edible coatings based on chitosan incorporated with three different concentrations of parsley, grape and blueberry pomace extracts, defined as a low-cost source of bioactive ingredients. Experimentally produced edible coatings were characterised by the following 
analyses: sensory analysis (quantitative descriptive analysis and hedonic analysis); colour parameters; scanning electron microscopy; and biological oxygen demand. Sensory and colour analyses allowed the evaluation of the real time consumers' preferences and acceptance; scanning electron microscopy showed the microproperties of the experimentally produced packaging; biological oxygen demand (BOD) values showed the biodegradable potential of the packaging.

\section{Materials and Methods}

\subsection{Materials}

Plant raw materials used in this study to produce extracts for the purpose of preparing edible coatings were purchased at the local market in Brno, Czech Republic. These were specifically parsley (Petroselinum), grown in the Czech Republic; blueberries (Vaccinium myrtillus L.), grown in Spain; and seedless red grapes (Crimson), grown in Chile. Low molecular weight chitosan, as well as other chemicals used in the analyses, were purchased from Sigma-Aldrich (St. Louis, MO, USA).

\subsection{Preparation of Extracts}

Firstly, the above-mentioned plant raw materials were juiced and byproducts (parsley, blueberries and grapes pomaces) were obtained in the form of pulp and husk. These byproducts were used to prepare extracts. Subsequently, $10 \mathrm{~g}$ of the byproduct were weighed into a beaker and poured into $100 \mathrm{~mL}$ of hot distilled water $\left(100{ }^{\circ} \mathrm{C}\right)$. After infusing for $10 \mathrm{~min}$, the extract was filtered and used to produce edible coating.

\subsection{Preparation of Edible Coatings}

The edible coatings were prepared using the modified method according to Jancikova et al. [36]. Firstly, $1.5 \mathrm{~g}$ of low molecular weight chitosan was weighed into a 250 $\mathrm{mL}$ beaker and subsequently dissolved in $1 \%$ lactic acid (the amount of lactic acid solution was variable depending on the amount of the extract). For the preparation of the coating without extracts as a control, $135 \mathrm{~mL}$ of $1 \%$ lactic acid was used. The samples were then transferred to magnetic stirrers and stirred for $15 \mathrm{~min}\left(50^{\circ} \mathrm{C}, 500 \mathrm{rpm}\right)$. The plant extracts were then added at 3 different volume concentrations (5\%,10\%,20\%) (the concentrations according to Jancikova et al. [3]) and the samples were stirred for an additional $5 \mathrm{~min}$. Glycerol $(0.75 \mathrm{~mL})$ was added as a plasticizer. Afterwards, the coating solution was poured into $150 \mathrm{~mm}$ diameter Petri dishes and left to dry for $48 \mathrm{~h}$. The composition of the edible coatings and related abbreviations are presented in Table 2.

Table 2. Composition of edible coatings.

\begin{tabular}{cc}
\hline Sample & Composition \\
\hline Ctrl & $1.5 \mathrm{~g}$ chitosan $+1 \%$ lactic acid $+0.75 \mathrm{~mL}$ glycerol \\
\hline BL_5 & $1.5 \mathrm{~g}$ chitosan $+1 \%$ lactic acid $+5 \%$ blueberry extract $+0.75 \mathrm{~mL}$ glycerol \\
\hline BL_10 & $1.5 \mathrm{~g}$ chitosan $+1 \%$ lactic acid $+10 \%$ blueberry extract $+0.75 \mathrm{~mL}$ glycerol \\
\hline BL_20 & $1.5 \mathrm{~g}$ chitosan $+1 \%$ lactic acid $+20 \%$ blueberry extract $+0.75 \mathrm{~mL}$ glycerol \\
\hline PA_5 & 1.5 g chitosan $+1 \%$ lactic acid $+5 \%$ parsley extract $+0.75 \mathrm{~mL}$ glycerol \\
\hline PA_10 & 1.5 g chitosan $+1 \%$ lactic acid $+10 \%$ parsley extract $+0.75 \mathrm{~mL}$ glycerol \\
\hline PA_20 & 1.5 g chitosan $+1 \%$ lactic acid $+20 \%$ parsley extract $+0.75 \mathrm{~mL}$ glycerol \\
\hline GR_5 & 1.5 g chitosan $+1 \%$ lactic acid $+5 \%$ red grape extract $+0.75 \mathrm{~mL}$ glycerol \\
\hline GR_10 & $1.5 \mathrm{~g}$ chitosan $+1 \%$ lactic acid $+10 \%$ red grape extract $+0.75 \mathrm{~mL}$ glycerol \\
\hline GR_20 & $1.5 \mathrm{~g}$ chitosan $+1 \%$ lactic acid $+20 \%$ red grape extract $+0.75 \mathrm{~mL}$ glycerol \\
\hline
\end{tabular}




\subsection{Sensory Analysis of Edible Coatings}

Sensory analyses were performed at the Department of Plant Origin Foodstuffs Hygiene and Technology of Faculty of Veterinary Hygiene and Ecology, University of Veterinary and Pharmaceutical Sciences Brno, Czech Republic. Both quantitative descriptive analysis and hedonic testing of prepared edible coatings were performed. The sensory analyses were performed in complete block design. Samples in the form of strips of edible packaging with approximate dimensions of $6 \mathrm{~cm} \times 2 \mathrm{~cm}$ were presented in random order on clear plastic Petri dishes identified by 3-digit numerical codes in a monadic sequential presentation scheme. At the same time, an additional survey of the probability of the prepared edible coatings being purchased if used with certain groups of food products was carried out.

\subsubsection{Quantitative Descriptive Analysis}

A quantitative descriptive analysis of prepared edible coatings was performed by a trained panel consisting of academic staff of the Department of Plant Origin Food Sciences. The average age of the 12 panellists was 33.5 years. A panel discussion on the most cited descriptors of edible packaging [37-41] was performed in order to select those that best characterize the product and to eliminate those that were not perceived by most panellists. After the discussion and selection of the descriptors, a training session on the selected edible coating descriptors' intensity scale preceded the quantitative descriptive analysis of the samples. Descriptors including colour intensity, surface character (smooth/rough), aroma intensity, and stickiness were evaluated. All attributes were quantified using a 9-point category ordinal scale with described extremes from 1 (no perception) to 9 (the highest intensity). The quantitative descriptive analysis was repeated three times.

\subsubsection{Hedonic Analysis}

Moderately trained panellists ( $n=55$; average age 29.2 years) consisting of students and employees of the Faculty of Veterinary Hygiene and Ecology were recruited for the hedonic analysis. Pleasantness of appearance, aroma, texture and overall pleasantness were evaluated $(1 \times$ evaluation $)$ using the 9 -point category ordinal hedonic scale. $(1=$ dislike extremely, $5=$ neither like nor dislike, $9=$ like extremely).

\section{Purchase Probability Evaluation}

The hedonic analysis also included a purchase probability evaluation for each group of food packed in the coatings produced for this study. A 5-point scale was used to evaluate the purchase probability: 1 = definitely would not eat the commodity in the analysed coating; 2 = probably would not eat the commodity in the coating; $3=$ not sure whether to eat the commodity in the coating; 4 = probably would eat the commodity in the coating; $5=$ certainly would eat the commodity in the analysed coating [37].

\subsection{Measuring the Colour Parameters of the Edible Coating}

The samples were placed on $150 \mathrm{~mm}$ diameter Petri dishes. Digital images of all experimental samples were acquired by a computer vision system. The images were taken under standard light conditions using 2 OSRAM DELUX L-1 $\times 18 \mathrm{~W}$ (OSRAM GmbH, Munich, Germany) lamps in a dark room. A Canon EOS 600D camera (Canon, Tokyo, Japan) mounted on a tripod (Fomei CS 920, Hradec Králové, Czech Republic) was used to take the images against a white background. The shooting was conducted in the Manual Mode, with an exposure time of 1/40, aperture F 5.6, image size L, sensitivity ISO 100 [42]. Ten images of each sample were obtained.

The images were processed by using the Nikon Imaging Software NIS-Elements BR 4.13.04 (Japan). The same region of interest (ROI) was selected for evaluating each image in the NIS-Elements. The colour characteristics-MeanRed, MeanGreen and MeanBlue-were measured, which were then converted to CIEL ${ }^{*}{ }^{*} b^{*}$ space, where $L^{*}$ stands for lightness, $\mathrm{a}^{*}$ indicates the position on red-green axis and $\mathrm{b}^{*}$ on yellow-blue axis. $\Delta \mathrm{E}$ as the colour 
difference between edible coatings with added extracts and control sample was calculated using CIE $\Delta$ E2000 equation [43,44].

\subsection{SEM Evaluation of the Surface of Edible Coatings}

The evaluation of the surface of the edible coating was performed after the gel formation on the conductive disc so as to minimise surface changes caused by bending or refraction during handling. For the index of refraction analysis, the edible coating was frozen with liquid nitrogen and mechanically broken. The fragments were stuck on carbon double-sided adhesive tape.

The samples were scanned with a MIRA3 TESCAN microscope (TESCAN ORSAY HOLDING, a.s., Brno, Czech Republic) at a voltage of $5.0 \mathrm{kV}$. Each sample was scanned three times. Images displaying a surface distortion were analysed using two micrographs obtained for each sample. This means that each sample was analysed at 6 randomly selected locations. The micrographs reported showed a magnification of $8 \mathrm{~K}, 80 \mathrm{~K}$, and $800 \mathrm{~K}$. A magnification of $25 \mathrm{~K}$ was used to view the images displaying the index of refraction of the coating.

\subsection{Evaluation of the Edible Coating Biodegradability by Mixed Culture}

Biological oxygen demand (BOD) values were determined by the aerobic system OxiTop $^{\circledR}$ (WTW, Weilheim, Germany) according to OECD guideline 301 F: Manometric Respirometry. A sample of edible coating in a mineral medium was inoculated (activated sludge) and incubated under aerobic conditions in the dark. The stock solutions for the mineral medium were prepared according to OECD guideline 301. Activated sewage sludge used in the experiments was taken from an activation tank at the wastewater treatment plant Modřice, 513,000 PE, Brno, Czech Republic. A measured volume of inoculated mineral medium ( $15 \mathrm{~mL}$ of sewage sludge and $28.5 \mathrm{~mL}$ of mineral medium), containing a known amount of the edible coatings $(0.1 \mathrm{mg} \pm 0.0050 \mathrm{mg})$ as the nominal sole source of organic carbon, was stirred in a closed flask at a constant temperature $20 \pm 1{ }^{\circ} \mathrm{C}$. The tests were terminated when the biodegradation curve had reached a plateau for at least three determinations. The consumption of oxygen is determined by measuring the change in pressure in the flask. Evolved carbon dioxide is absorbed in sodium hydroxide. The amount of oxygen taken up by the microbial population during biodegradation of the test substance (corrected for uptake by blank inoculum, run in parallel) is expressed as a $\mathrm{BOD}$ in $\mathrm{mg} / \mathrm{L} / \mathrm{g}_{\mathrm{dw}}$. The analysis was performed in triplicate.

\subsection{Statistical Analysis}

As the experimental design in the sensory analyses, a complete block design was used. Statistical analyses of sensory data were performed using the SensoMineR package for R software (The R Foundation for Statistical Computing, Vienna, Austria). Principal component analysis (PCA) was selected for the sensory data evaluation. The resulting colour parameters were statistically evaluated using the Unistat Tukey-HSD test procedure. Spearman's correlation coefficient was used to express non-parametric correlations between sensory descriptors and colour parameters obtained by measuring instruments. A k-sample comparison of variances test (XLSTAT, Addinsoft, FR, version 2021) with a significance level $\alpha=0.05$ was used for the statistical processing of the total area and distance of cracks obtained by SEM. Outlying values were removed before the analysis by means of the Grubbs' test of outliers $(p<0.05)$.

\section{Results and Discussion}

\subsection{Results of the Sensory Analysis of Edible Coatings}

The results of the sensory analysis are shown in two types of graphs: score plots for the mean points and variables factor maps. By score plots, difference vs. similarity between individual analysed samples is visualized. Variable factor maps visualize the relation between the principal components and the evaluated descriptors. 
The principal component analysis (PCA) emphasized the differences between the experimenally produced edible coatings since the distribution of samples in score plots (both quantitative descriptive and hedonic analysis) indicated dependence on extract concentrations and extract type (Figures 1 and 2). These findings are important due to the fact that sensory properties, as the most important factor for the consumers' acceptance, can be affected by the proper choice of plant extract.

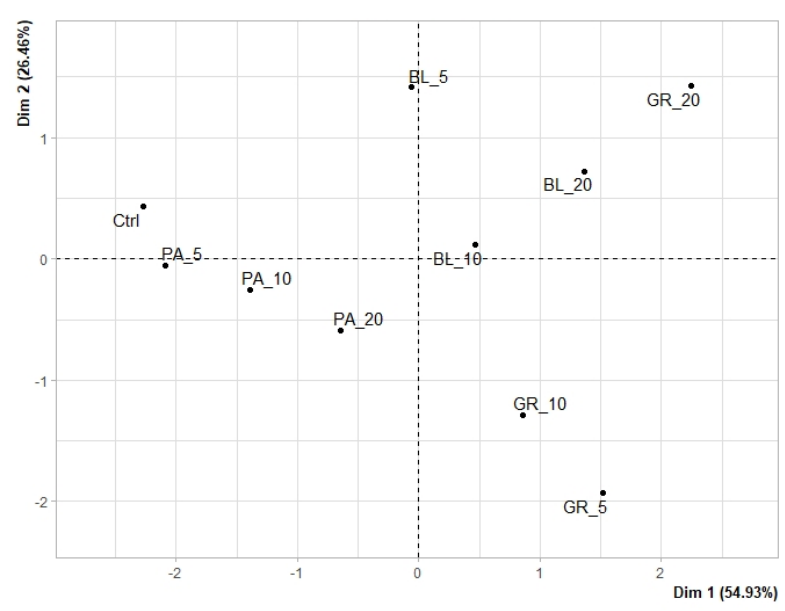

(a)

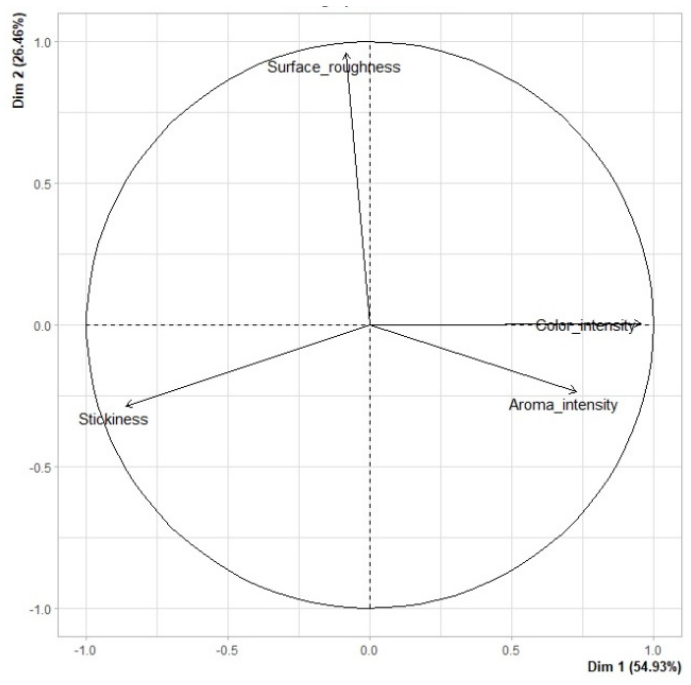

(b)

Figure 1. The results of PCA of quantitative descriptive analysis of edible coatings: (a) Score plot for the mean points (BL_5, edible coating with $5 \%$ of blueberry extract; BL_10, edible coating with $10 \%$ of blueberry extract; BL_20, edible coating with $20 \%$ of blueberry extract; GR_5, edible coating with 5\% of red grape extract; GR_10, edible coating with $10 \%$ of red grape extract; GR_20, edible coating with 20\% of red grape extract; PA_5, edible coating with 5\% of parsley extract; PA_10, edible coating with $10 \%$ of parsley extract; PA_20, edible coating with $20 \%$ of parsley extract; Ctrl, control = edible coating without added extract). (b) Variables factor map.

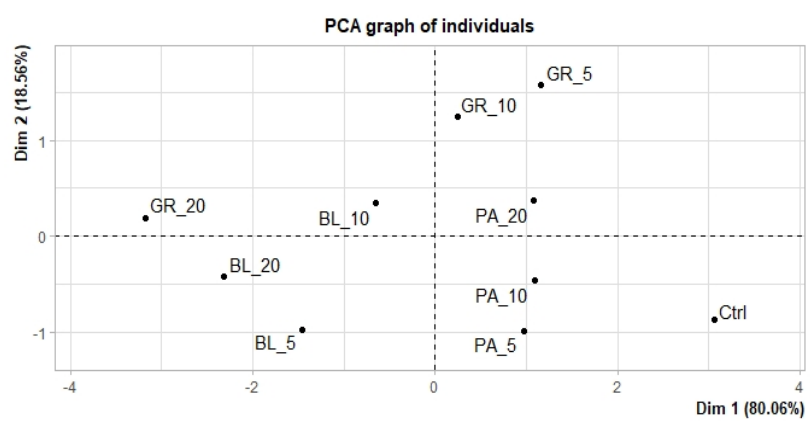

(a)

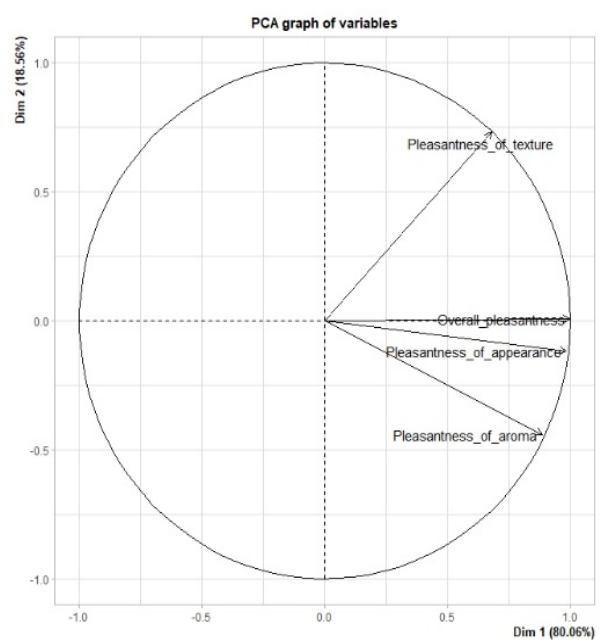

(b)

Figure 2. The results of PCA of hedonic analysis of edible coatings: (a) Score plot for the mean points (BL_5, edible coating with $5 \%$ of blueberry extract; BL_10, edible coating with $10 \%$ of blueberry extract; BL_20, edible coating with $20 \%$ of blueberry extract; GR_5, edible coating with 5\% of red grape extract; GR_10, edible coating with $10 \%$ of red grape extract; GR_20, edible coating with 20\% of red grape extract; PA_5, edible coating with 5\% of parsley extract; PA_10, edible coating with $10 \%$ of parsley extract; PA_20, edible coating with $20 \%$ of parsley extract; Ctrl, control = edible coating without added extract). (b) Variables factor map. 


\subsubsection{Quantitative Descriptive Analysis}

Figure 1 shows the results of the quantitative descriptive analysis of the edible coatings. Both the location of each sample on the map of samples (Figure 1a) and the statistically significant $(p<0.05)$ differences between the edible coatings shown by Table 3 make it clear that the samples of edible coatings differed in many statistically significant aspects. The edible coatings containing grape and blueberry pomace in all concentrations (with the exception of the lowest $5 \%$ concentration of blueberry pomace) had statistically significantly $(p<0.05)$ higher levels of colour intensity. This was due to the typically high levels of anthocyanin pigments contained in both types of fruit [45]. The mean values of aroma intensity for all samples had a narrower range (3.46-4.77), with the control sample having a statistically significantly lower value and the samples of the coatings containing grape pomace having statistically significantly higher values. Grapes belong to the types of fruit with a typically more intense aroma. This intense aroma of grapes is generally one of the key factors for its higher sensory acceptability for consumers despite certain differences in the specific profile of volatile substances depending on the cultivar and the degree of maturity [46]. The mean values in the evaluation of the descriptor "surface roughness" ranged from 2.40 to 5.86, with several statistically significant differences. Samples GR_20, BL_20 and BL_5 showed statistically significantly higher roughness values. On the other hand, the samples with the two lowest concentrations of grape pomace (GR_5 and GR_10) had the lowest roughness. All analysed samples of edible coatings were characterised by a relatively low stickiness (2.11-3.14), with a statistically significantly lower stickiness documented only for sample GR_20 and with parsley pomace slightly increasing the level of stickiness (statistically significantly higher stickiness of samples PA_5 and PA_10 [3.14 and 3.05, respectively]). To be acceptable for consumer and commercial purposes, edible coatings should not be sticky; moreover, a smooth and glossy surface is desirable, especially for fruit coatings $[8,47]$.

Table 3. Matrix with the $p$-values of the Hotelling's T2 tests for each pair of edible film formulations (quantitative descriptive analysis).

\begin{tabular}{ccccccccccc}
\hline & B1_10 & BL_20 & BL_5 & Ctrl & GR_10 & GR_20 & GR_5 & PA_10 & PA_20 & PA_5 \\
\hline BL_10 & 1.00 & 0.06 & $p<0.01$ & $p<0.01$ & $p<0.01$ & $p<0.01$ & $p<0.01$ & $p<0.05$ & $p<0.05$ & $p<0.01$ \\
BL_20 & 0.06 & 1.00 & $p<0.05$ & $p<0.01$ & $p<0.01$ & 0.08 & $p<0.01$ & $p<0.01$ & $p<0.01$ & $p<0.01$ \\
BL_5 & $p<0.01$ & $p<0.05$ & 1.00 & $p<0.01$ & $p<0.01$ & $p<0.05$ & $p<0.01$ & $p<0.01$ & $p<0.01$ & $p<0.01$ \\
Ctr1 & $p<0.01$ & $p<0.01$ & $p<0.01$ & 1.00 & $p<0.01$ & $p<0.01$ & $p<0.01$ & 0.14 & $p<0.05$ & 0.48 \\
GR_10 & $p<0.01$ & $p<0.01$ & $p<0.01$ & $p<0.01$ & 1.00 & $p<0.01$ & 0.21 & $p<0.01$ & $p<0.05$ & $p<0.01$ \\
GR_20 & $p<0.01$ & 0.08 & $p<0.05$ & $p<0.01$ & $p<0.01$ & 1.00 & $p<0.01$ & $p<0.01$ & $p<0.01$ & $p<0.01$ \\
GR_5 & $p<0.01$ & $p<0.01$ & $p<0.01$ & $p<0.01$ & 0.21 & $p<0.01$ & 1.00 & $p<0.01$ & $p<0.01$ & $p<0.01$ \\
PA_10 & $p<0.05$ & $p<0.01$ & $p<0.01$ & 0.14 & $p<0.01$ & $p<0.01$ & $p<0.01$ & 1.00 & 0.24 & 0.41 \\
PA_20 & $p<0.05$ & $p<0.01$ & $p<0.01$ & $p<0.05$ & $p<0.05$ & $p<0.01$ & $p<0.01$ & 0.24 & 1.00 & $p<0.05$ \\
PA_5 & $p<0.01$ & $p<0.01$ & $p<0.01$ & 0.48 & $p<0.01$ & $p<0.01$ & $p<0.01$ & 0.41 & $p<0.05$ & 1.00 \\
\hline
\end{tabular}

* Statistically significant differences between the groups are emphasized with green colour. BL_5, edible film with $5 \%$ of blueberry extract; BL_10, edible film with $10 \%$ of blueberry extract; BL_20, edible film with $20 \%$ of blueberry extract; GR_5, edible film with $5 \%$ of red grape extract; GR_10, edible film with $10 \%$ of red grape extract; GR_20, edible film with 20\% of red grape extract; PA_5, edible film with 5\% of parsley extract; PA_10, edible film with $10 \%$ of parsley extract; PA_20, edible film with $20 \%$ of parsley extract; Ctrl, control = edible film without added extract.

\subsubsection{Hedonic Analysis}

Figure 2 and Table 4 show the results of the hedonic analysis of the edible coatings. Figure 2 shows a graph with the results of the main component analysis explaining the $98.62 \%$ variability by using two main components, one accounting for $80.06 \%$ and the other for $18.56 \%$ of the variability. The factor map of variables shows a close correlation between the overall evaluation and the descriptor of appearance. Table 4 shows the treated average values of descriptors obtained by the hedonic evaluation. The values highlighted in green represent a statistically significantly better rating $(p<0.05)$; the values highlighted in orange represent a statistically significantly worse rating. Both the location of each 
sample on the map of samples (Figure $2 b$ ) and Table 4 make it clear that the samples of edible coatings differed in many statistically significant $(p<0.05)$ aspects in the evaluation of pleasantness. The control sample, which did not contain any added plant pomace, achieved statistically significantly $(p<0.05)$ higher values in the descriptors pleasantness of appearance, pleasantness of aroma and overall evaluation. This may be due to the less intense colour and aroma of this sample, which, due to its neutral character, does not leave a disturbing impression, which is a key quality of an edible coating $[48,49]$.

Table 4. Adjusted mean of hedonic evaluation of edible coatings.

\begin{tabular}{ccccc}
\hline & Pleasantness of Texture & Pleasantness of Aroma & Pleasantness of Appearance & Overall Pleasantness \\
\hline GR_20 & 5.031 & 4.456 & 4.048 & 4.488 \\
BL_20 & 4.919 & 4.604 & 4.048 & 4.655 \\
BL_5 & 5.012 & 4.771 & 4.770 & 5.062 \\
BL_10 & 5.568 & 4.623 & 4.844 & 5.229 \\
GR_10 & 6.568 & 4.642 & 4.918 & 5.414 \\
PA_20 & 6.031 & 4.827 & 5.437 & 5.803 \\
PA_10 & 5.808 & 5.067 & 5.474 & 5.766 \\
PA_5 & 5.586 & 5.123 & 5.788 & 5.933 \\
GR_5 & 6.827 & 4.827 & 5.529 & 5.859 \\
Ctrl & 6.049 & 5.549 & 6.511 & 6.322 \\
\hline
\end{tabular}

BL_5, edible coating with $5 \%$ of blueberry extract; BL_10, edible coating with $10 \%$ of blueberry extract; BL_20, edible coating with $20 \%$ of blueberry extract; GR_5, edible coating with 5\% of red grape extract; GR_10, edible coating with 10\% of red grape extract; GR_20, edible coating with $20 \%$ of red grape extract; PA_5, edible coating with $5 \%$ of parsley extract; PA_10, edible coating with $10 \%$ of parsley extract; PA_20, edible coating with $20 \%$ of parsley extract; Ctrl, control = edible coating without added extract.

In the overall evaluation, another four samples containing parsley pomace in all concentrations and a sample containing $5 \%$ grape pomace achieved a statistically significantly $(p<0.05)$ better evaluation. Samples PA_5 and GR_5 also achieved a statistically significantly $(p<0.05)$ better evaluation for the descriptor pleasantness of appearance. The samples with the highest $(20 \%)$ concentration of grape and blueberry pomace had the lowest overall evaluation. These two samples also had statistically significantly $(p<0.05)$ lower values of pleasantness of appearance and texture. Most likely, this was due to the high intensity of the colour, which prevented the achievement of a neutral character without any disturbing qualities.

The pleasantness of edible coating samples in individual descriptors was evaluated using a 9-point category scale: $1=$ completely unpleasant; $5=$ neutral; $9=$ completely pleasant. Scores below 5 were considered as indicative of rejection of the sample due to unsatisfactory sensory quality $[37,48]$. From the point of view of the overall evaluation, only the samples with the highest $(20 \%)$ concentrations of grape and blueberry pomace extract were rejected. However, in terms of individual descriptors, more samples were assessed as unsatisfactory (scoring less than 5).

Apart from the control sample, only two samples containing pomaces (PA_5, PA_10) had values higher than five for all hedonic descriptors at the same time, and were therefore not considered rejected in terms of sensory quality. However, the values obtained for all four hedonic descriptors ranged in narrow intervals, indicative of a relative similarity of the samples to each other in the absence of any extreme differences between the values. The overall evaluation values ranged in the interval of (4.49-6.32); this indicates that even the samples with the statistically significantly best evaluation were only slightly pleasant in the overall evaluation. However, some studies consider a value of 4 as the limit for product acceptability in terms of a sensory trait $[38,50]$. If this milder criterion is applied, all samples of edible coatings analysed in our study could be considered acceptable in terms of sensory quality. In a study performed by Gutiérrez and Álvarez [51], edible films based on native plantain flour ( $2 \%$ ) with glycerol (1.5\%), with added different concentrations of Aloe vera gel $(0,2,4$ and $6 \%)$ achieved lower values of overall acceptability (3.8-4.5 on a $0-10$ scale). Karača et al. [52] developed alginate- and pectin-based edible films combining alginate and pectin with various proteins in immortelle (Helichrysum italicum) extract abundant in 
polyphenols. These films achieved a broader span of overall acceptability values (2-7.5 on a 1-9 scale) with the highest values for alginate- and pectin-based edible films with whey protein isolate and alginate-based film with hemp protein.

Probability of Purchasing Commodities in Edible Coating

The results of the analysis of the probability of purchasing different groups of food commodities packaged in the edible coatings are shown in Table 5. As most of the values were lower than 3 , it is clear that the evaluators could not imagine the use of the analysed edible coatings for groups of commodities such as meat products, dairy products (cheese), baked products, or fruits and vegetables. Apart from the control sample, samples PA_5 and PA_10 had the highest values in terms of buying intention. The use of sample PA_5 for packaging vegetables and dairy products (cheese) and the use of sample PA_10 for packaging fruit and vegetables scored 3, indicating panellists' indifference towards such products. Out of the samples containing plant extracts, the use of samples with $5 \%$ and $10 \%$ concentrations of parsley pomace was therefore the most conceivable for the panellists.

Table 5. Adjusted mean scores of the probability of purchasing a certain commodity in an edible coating.

\begin{tabular}{cccccc}
\hline & Meat Products & Vegetables & Fruit & Milk Products (Cheese) & Bakery Products \\
\hline BL_10 & 1.655 & 2.121 & 2.117 & 1.600 & 1.467 \\
BL_20 & 1.884 & 1.950 & 2.089 & 1.629 & 1.524 \\
GR_20 & 2.055 & 1.836 & 1.974 & 2.000 & 1.524 \\
GR_10 & 1.941 & 2.207 & 2.174 & 2.057 & 1.609 \\
GR_5 & 2.084 & 2.264 & 2.231 & 1.943 & 1.724 \\
BL_5 & 2.027 & 2.379 & 2.546 & 2.257 & 1.838 \\
PA_20 & 2.141 & 2.721 & 2.517 & 2.315 & 1.867 \\
PA_10 & 2.255 & 3.064 & 3.003 & 2.715 & 2.295 \\
PA_5 & 2.255 & 3.121 & 2.946 & 3.143 & 2.381 \\
Ctrl & 2.284 & 3.35 & 3.403 & 3.229 & 2.495 \\
\hline
\end{tabular}

BL_5, edible coating with 5\% of blueberry extract; BL_10, edible coating with $10 \%$ of blueberry extract; BL_20, edible coating with $20 \%$ of blueberry extract; GR_5, edible coating with 5\% of red grape extract; GR_10, edible coating with 10\% of red grape extract; GR_20, edible coating with $20 \%$ of red grape extract; PA_5, edible coating with $5 \%$ of parsley extract; PA_10, edible coating with $10 \%$ of parsley extract; PA_20, edible coating with $20 \%$ of parsley extract; Ctrl, control = edible coating without added extract.

\subsection{Results of Measuring Colour Parameters}

Figure 3 contains images of edible coatings with added plant pomace. The results of the measurement of colour parameters (Table 6) demonstrate a statistically significant difference between almost all used additions and concentrations and the control sample without added plant pomace.

Table 6. Parameters of edible coating colour.

\begin{tabular}{|c|c|c|c|c|}
\hline \multicolumn{5}{|c|}{ Concentration of Plant Extract } \\
\hline Blueberry Extract & $5 \%$ & $10 \%$ & $20 \%$ & Control \\
\hline$L^{*}$ & $53.443 \pm 0.440$ & $43.781 \pm 1.132$ & $33.124 \pm 0.790$ & $66.690 \pm 0.441$ \\
\hline$a^{*}$ & $3.757 \pm 0.087$ & $14.324 \pm 0.157$ & $23.924 \pm 0.221$ & $-2.185 \pm 0.066$ \\
\hline$b^{*}$ & $44.056 \pm 0.177$ & $46.980 \pm 0.695$ & $41.485 \pm 0.589$ & $12.773 \pm 0.222$ \\
\hline$\Delta \mathrm{E}$ & $18.672 \pm 0.238$ & $28.073 \pm 0.756$ & $39.297 \pm 0.651$ & - \\
\hline Parsley Extract & $5 \%$ & $10 \%$ & $20 \%$ & Control \\
\hline$L^{*}$ & $66.998 \pm 0.276^{\mathrm{a}}$ & $65.683 \pm 0.618$ & $62.750 \pm 0.286$ & $66.690 \pm 0.441^{a}$ \\
\hline$a^{*}$ & $-2.863 \pm 0.068$ & $-3.281 \pm 0.049$ & $-2.243 \pm 0.054^{b}$ & $-2.185 \pm 0.066^{b}$ \\
\hline$b^{*}$ & $18.627 \pm 0.136$ & $25.517 \pm 0.174$ & $32.124 \pm 0.235$ & $12.773 \pm 0.222$ \\
\hline$\Delta \mathrm{E}$ & $3.4858 \pm 0.133$ & $6.927 \pm 0.200$ & $10.253 \pm 0.202$ & - \\
\hline Grape Extract & $5 \%$ & $10 \%$ & $20 \%$ & Control \\
\hline$L^{*}$ & $56.996 \pm 0.616^{c}$ & $57.204 \pm 0.721^{c}$ & $51.778 \pm 0.788$ & $66.690 \pm 0.441$ \\
\hline$a^{*}$ & $1.541 \pm 0.106$ & $1.177 \pm 0.133$ & $6.178 \pm 0.118$ & $-2.185 \pm 0.066$ \\
\hline$b^{*}$ & $43.223 \pm 0.266$ & $44.021 \pm 0.319$ & $48.256 \pm 0.471$ & $12.773 \pm 0.222$ \\
\hline$\Delta \mathrm{E}$ & $16.271 \pm 0.229^{\mathrm{d}}$ & $16.335 \pm 0.244^{\mathrm{d}}$ & $20.892 \pm 0.350$ & - \\
\hline
\end{tabular}

Equal letters in the same row indicate no statistically significant differences $(p<0.01)$. 

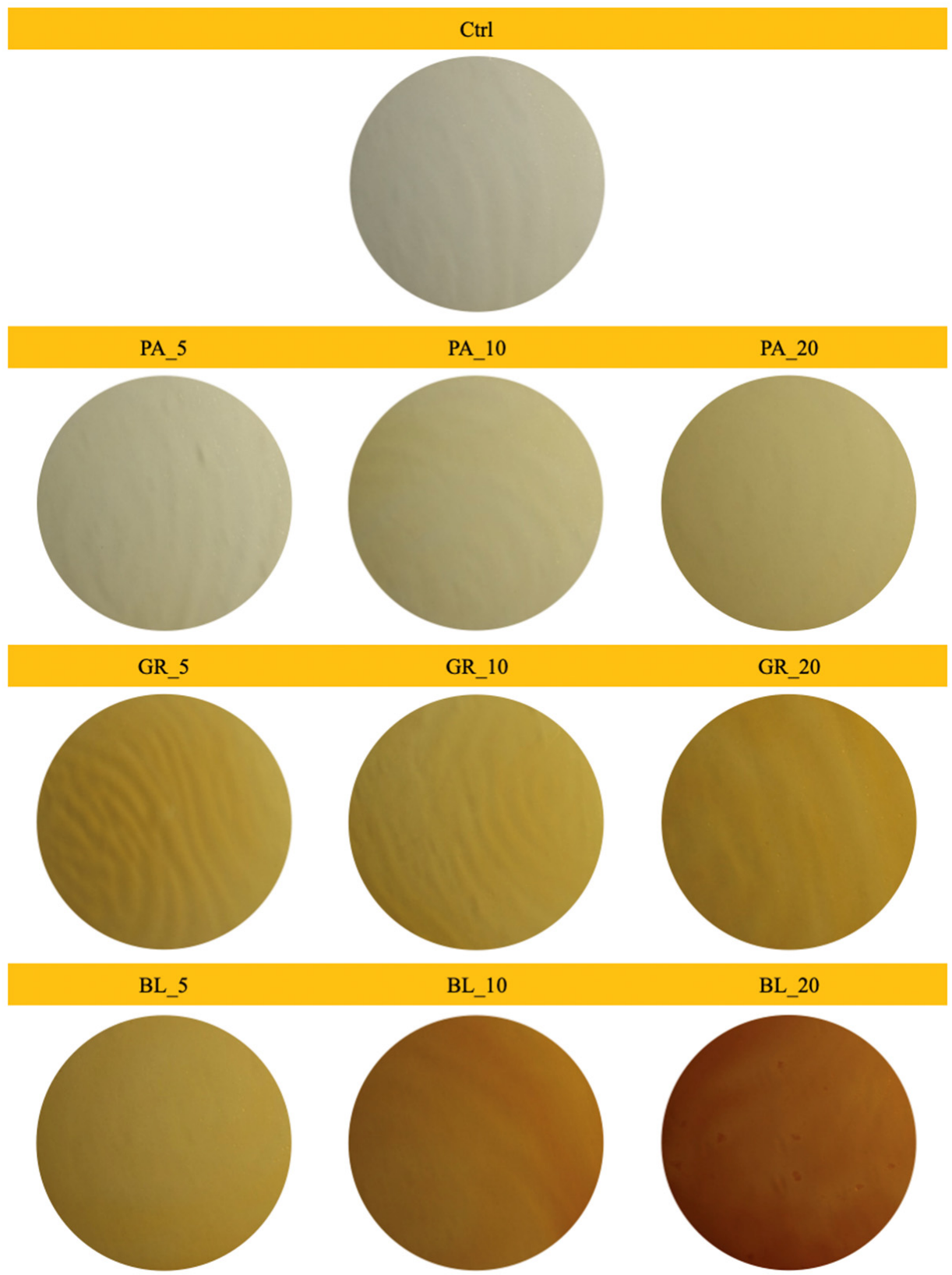

Figure 3. Digital images of edible coatings used for colour analysis (BL_5, edible coating with 5\% of blueberry extract; BL_10, edible coating with $10 \%$ of blueberry extract; BL_20, edible coating with $20 \%$ of blueberry extract; GR_5, edible coating with 5\% of red grape extract; GR_10, edible coating with $10 \%$ of red grape extract; GR_20, edible coating with $20 \%$ of red grape extract; PA_5, edible coating with $5 \%$ of parsley extract; PA_10, edible coating with $10 \%$ of parsley extract; PA_20, edible coating with $20 \%$ of parsley extract; Ctrl, control = edible coating without added extract).

In the case of coatings that contained blueberry pomace, the value of $a^{*}$ increased with increasing concentration, whose positive values indicate an increasing proportion of the red component. Blueberries are rich in anthocyanins, coloured substances valued for their antioxidant capacity [52]. In an acidic environment, anthocyanins are red, but as the $\mathrm{pH}$ increases, their colour changes to blue [53]. The red colour of the coatings evaluated by us was therefore also partly due to the addition of lactic acid to the coatings. With the increasing concentration of the added blueberry pomace, the lightness value $\left(L^{*}\right)$ further decreased. A statistically significant difference $(p<0.01)$ between the samples with different concentrations of added blueberry pomace was demonstrated for the parameters $L^{*}, a^{*}$ 
and $b^{*}$, as was a statistically significant difference in the parameter $\Delta \mathrm{E}$ (Figure 4 ), which describes the degree of difference between individual samples and the control without the addition of blueberry pomace. However, the lower stability of anthocyanins is a potential disadvantage of using blueberry pomace in edible coatings [54].

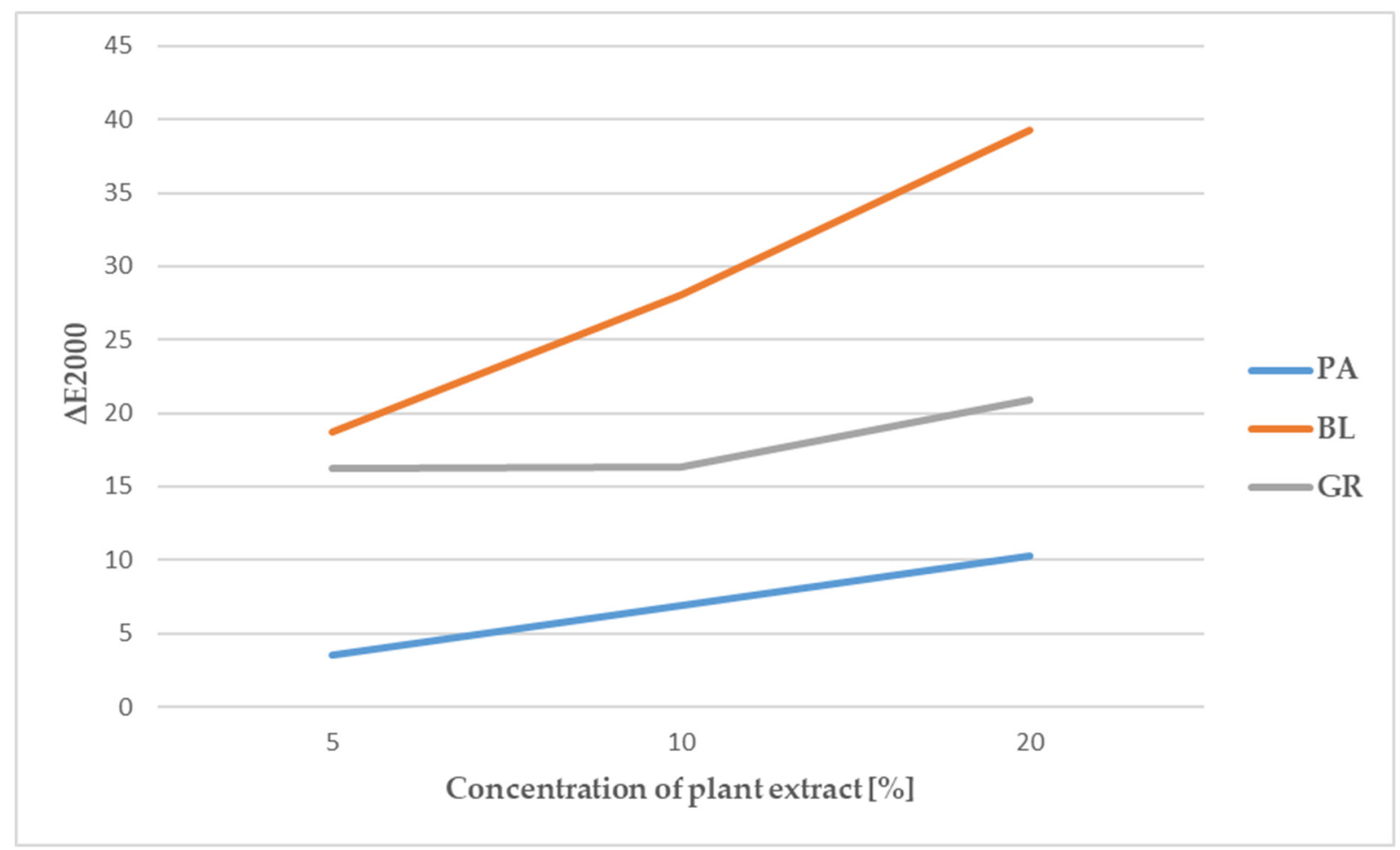

Figure 4. Colour difference between the control and the edible coating samples with added extracts (PA, parsley extract; BL, blueberry extract; GR, grape extract).

The evaluation of the colour parameters of the edible coatings with added parsley pomace demonstrated a statistically significant difference for most samples, both between individual samples and in comparison with the control. Only between the sample with the addition of $5 \%$ parsley pomace and the control sample was no statistically significant difference in the $L^{*}$ parameter demonstrated, as was between the sample with the addition of $20 \%$ of the same pomace and the control sample in the $a^{*}$ parameter. The positive values of the parameter $b^{*}$ correspond to the presence of the yellow colour [44]. In the case of samples of edible coatings containing parsley pomace, the parameters of their colour, in particular the parameter $b^{*}$, were influenced by the presence of hydroxy derivatives of flavones and isoflavones, which belong to the yellow pigments. Apigenin, which is a natural bioactive component of parsley (Petroselinum crispum L.) with many therapeutic qualities, is also included in this group [55]. It is a flavonoid found in many species of fruit, vegetables, and herbs, but parsley is one of its most important sources [42].

In the case of edible coatings with added red grape pomace, no statistically significant difference in lightness $\left(L^{*}\right)$ was demonstrated between samples with the addition of 5 and $10 \%$ of the pomace (Table 6). As in the case of blueberries, the characteristic pigments contained in grape berries include anthocyanins, of which malvidin accounts for $68 \%$ [33,56,57]. As already mentioned, the colour of anthocyanins varies from red to blue depending on the $\mathrm{pH}$ [53]. The addition of grape pomace containing anthocyanins in combination with the used lactic acid led to an increase in the value of the parameter $a^{*}$. In their study, Burin at el. [58] documented a robust positive correlation between the red colour and the total level of anthocyanins in grape juice. 
In order to compare the control with samples with added pomace, the value of $\Delta \mathrm{E} 2000$ was calculated. The results showed that the type and concentration of the pomace used had a statistically significant effect $(p<0.01)$ on the $\Delta E 2000$ values. In all cases, the value of $\Delta \mathrm{E} 2000$ was greater than 1 , which is the minimum value allowing the human eye to distinguish the difference [59]. The largest difference was obtained in samples with added blueberry and grape pomace. However, the edible coating samples containing grape pomace did not demonstrate a linear increase depending on the concentration of the added pomace. The lowest values of $\Delta \mathrm{E} 2000$ were found in samples of edible coatings containing parsley pomace, with $\Delta \mathrm{E} 2000$ ranging from 3.5 for the concentration of $5 \%$ to 10.3 for the concentration of $20 \%$ of the added pomace.

However, the mere fact that the analysed samples of edible coatings with added plant pomace differed in colour from the control sample without added pomace does not automatically mean worse properties or lower usability of such coatings. Although the usual aim is to produce edible coatings that would least affect the sensory properties, such as the appearance and colour of the products, in certain specific cases, a darker colour may also be an advantage. Veiga-Santos et al. [60] believe that a darker colour can reduce the amount of light-induced oxidation of the product, and thus contribute to an improved protection of the food from oxidation, which could be particularly useful for food with a higher fat content. Another alternative solution may be the application of edible coatings with a more intense colour as secondary food coating [51]. Another possibility is the potential use of coatings with a more pronounced colour for enhancing the natural colour of similarly coloured food, thus assisting in their marketing apart from their primary protective purposes. Similarly, Benítez et al. [61] described a positive perception of edible coatings with aloe vera gel characterised by a greenish colour due to the contained chlorophyll when used to package kiwi slices.

\subsection{Correlations between Sensory and Instrumental Colour Evaluations}

Spearman's correlation coefficient was used to express non-parametric correlations between sensory descriptors and colour parameters obtained by measuring instruments. According to Table 7, a number of statistically highly significant correlations $(p<0.01)$ were demonstrated between sensory descriptors related to the appearance and instrumentally assessed colour parameters of edible coatings with added plant pomace.

Table 7. Spearman's correlation coefficients between sensory appearance descriptors and instrumental colour parameters of edible coating samples with added plant extracts.

\begin{tabular}{cccc}
\hline & Colour Intensity & Pleasantness of Appearance & Overall Pleasantness \\
\hline \multicolumn{4}{c}{ Parsley extract } \\
\hline$L^{*}$ & $-0.553^{* *}$ & $0.207^{*}$ & 0.149 \\
$a^{*}$ & $-0.184^{*}$ & 0.069 & 0.073 \\
$b^{*}$ & $0.674^{* *}$ & $-0.356^{* *}$ & -0.153 \\
\hline \multicolumn{5}{c}{ Grape extract } \\
\hline$L^{*}$ & $-0.715^{* *}$ & $0.426^{* *}$ & $0.330^{* *}$ \\
$a^{*}$ & $0.638^{* *}$ & $-0.395^{* *}$ & $-0.281^{* *}$ \\
$b^{*}$ & $0.815^{* *}$ & $-0.428^{* *}$ & $-0.340^{* *}$ \\
\hline & & $0.461^{* *}$ & \\
\hline$L^{*}$ & $-0.857^{* *}$ & $-0.459^{* *}$ & $-0.316^{* *}$ \\
$a^{*}$ & $0.845^{* *}$ & $-0.275^{* *}$ & $-0.175^{*}$ \\
$b^{*}$ & $0.381^{* *}$ & Blueberry extract & \\
\hline
\end{tabular}

* Asterisk next to the numerical value indicates statistically significant difference $(p<0.05)$; ${ }^{* *}$ Two asterisks next to the numerical value indicate statistically very significant difference $(p<0.01)$. 
Hence, we may say that higher values of the L parameter suggest a higher sensory pleasantness of appearance, as does a lower degree of red/yellow colour of the edible coating. These instrumentally evaluated colour parameters accounted for a $21-46 \%$ variability of the sensory pleasantness of the appearance. The same trend was also followed by the correlation coefficients of the overall sensory pleasantness and the instrumentally evaluated colour parameters of the edible coatings; however, the values of the latter were lower and accounted for an 18-34\% variability of the overall pleasantness in cases with a proven statistical significance. The values of instrumentally evaluated colour parameters of the edible coatings whose pleasantness was assessed by the sensory analysis as statistically significantly better are shown in Section 3.2.

\subsection{Results of SEM Evaluation of the Surface of Edible Coatings}

The scanning electron microscopy (SEM) technique was used to describe the microstructure, especially the occurrence of possible cracks, their area and the distance between these individual cracks. SEM images of the surfaces of the edible coatings as well as their cross-sections are represented in Figure 5a-d.

Figure 6 documents the average size of the cracks in the surface of the formed gel. Figure 7 documents the distance between the cracks.

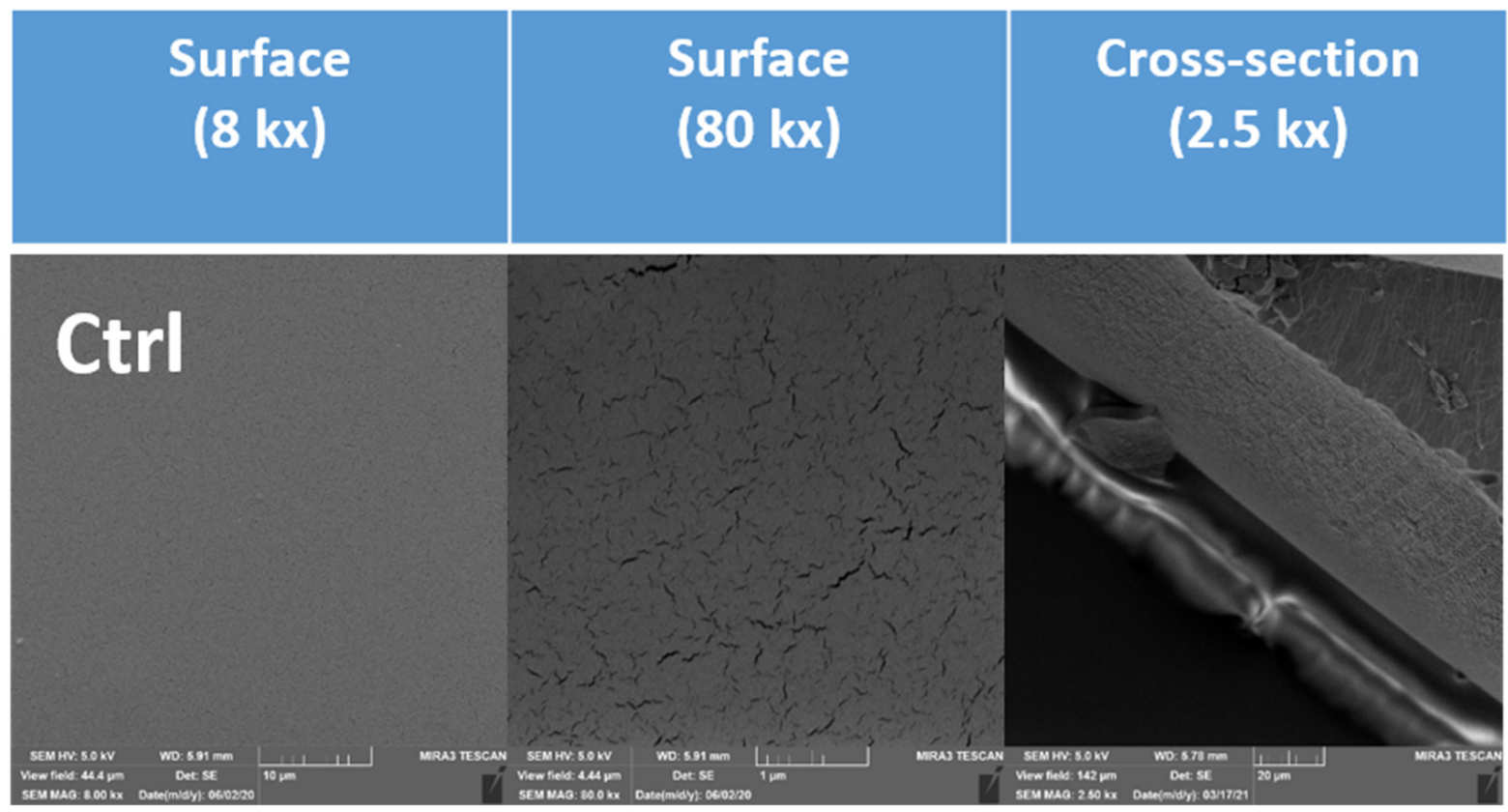

(a)

Figure 5. Cont. 


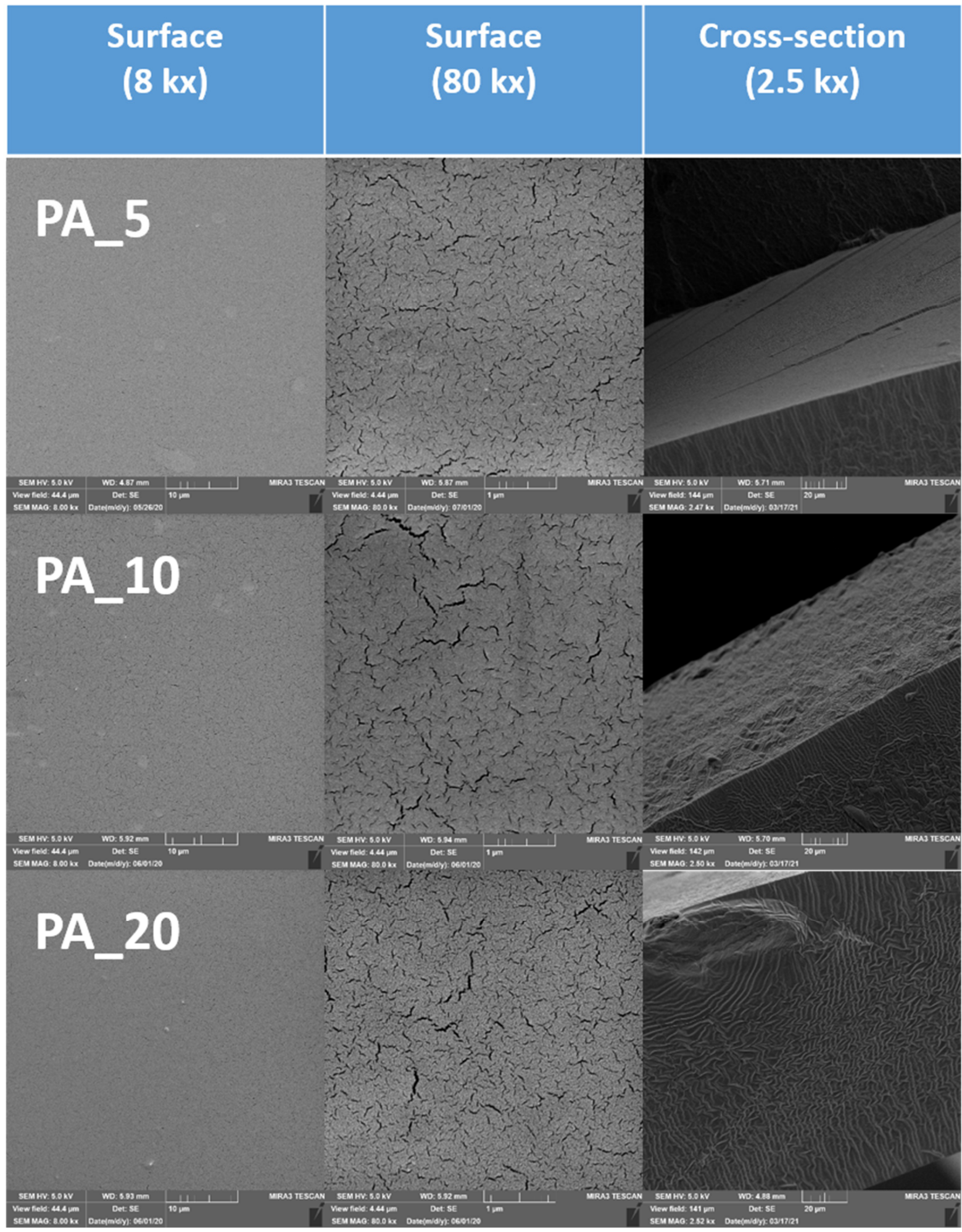

(b)

Figure 5. Cont. 


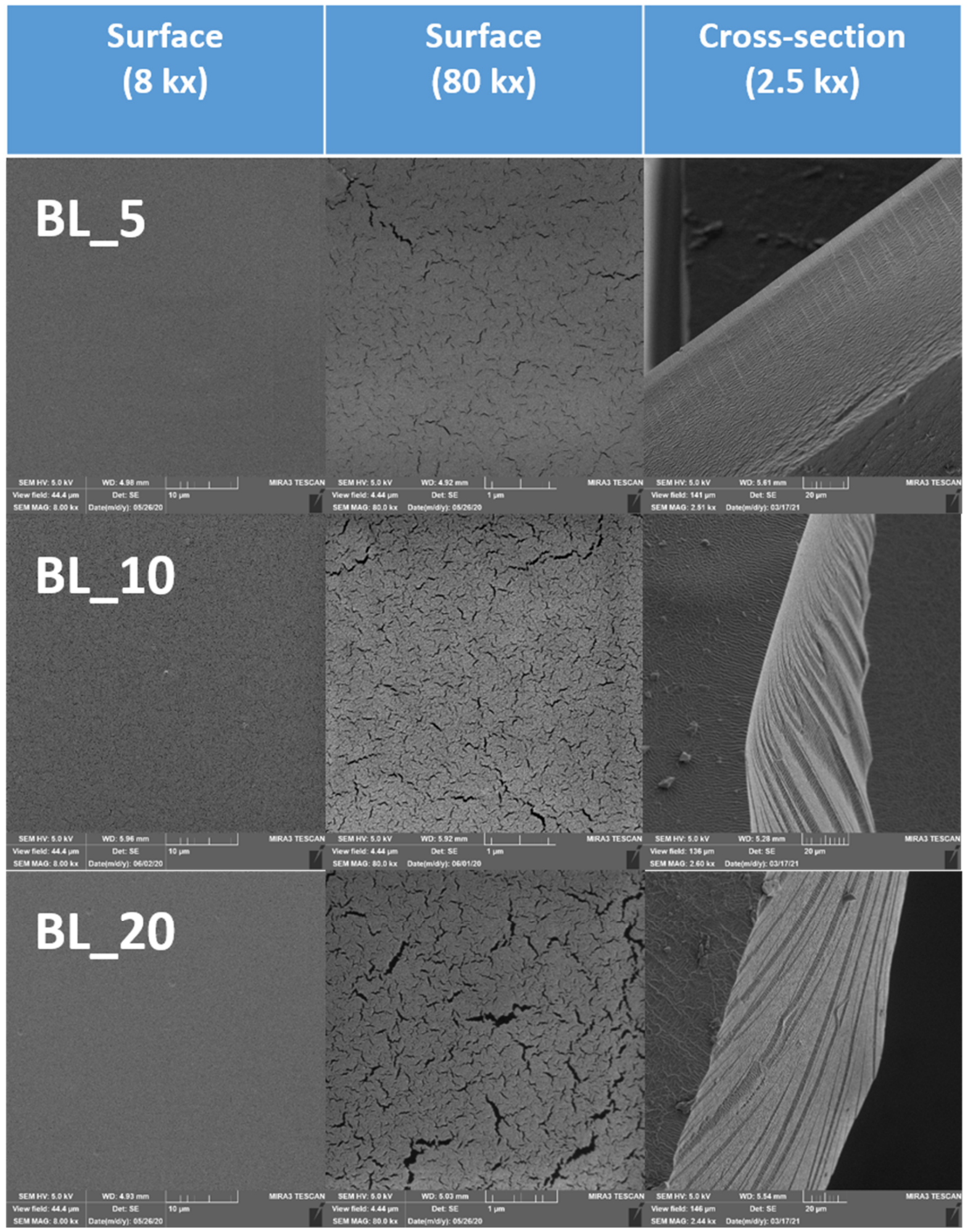

(c)

Figure 5. Cont. 


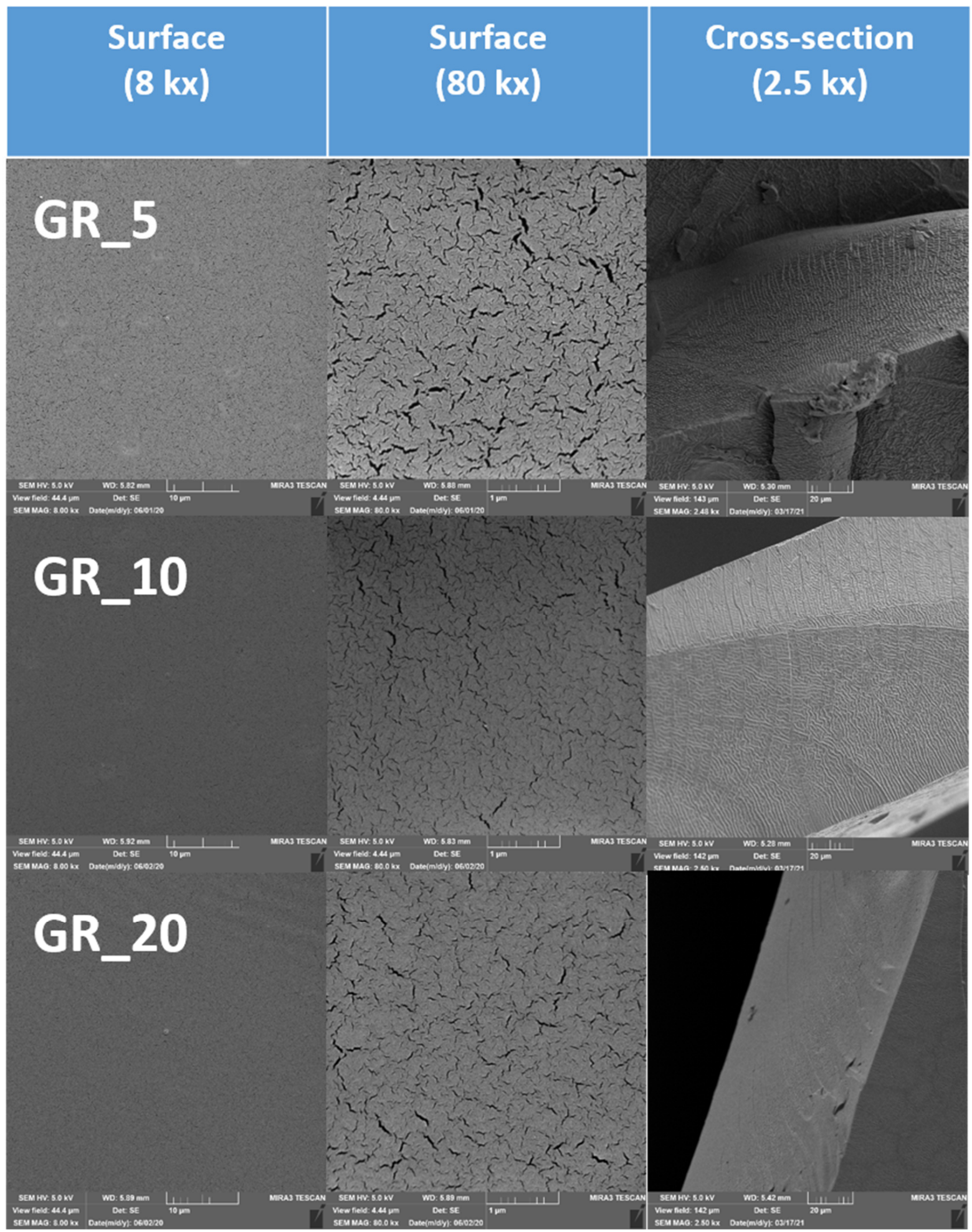

(d)

Figure 5. SEM images of edible coatings: surface images and cross-sections. (a) Ctrl, control = edible coating without added extract. (b) PA_5, edible coating with 5\% of parsley extract; PA_10, edible coating with 10\% of parsley extract; PA_20, edible coating with $20 \%$ of parsley extract. (c) BL_5, edible coating with $5 \%$ of blueberry extract; BL_10, edible coating with $10 \%$ of blueberry extract; BL_20, edible coating with $20 \%$ of blueberry extract. (d) GR_5, edible coating with $5 \%$ of red grape extract; GR_10, edible coating with $10 \%$ of red grape extract; GR_20, edible coating with $20 \%$ of red grape extract. 


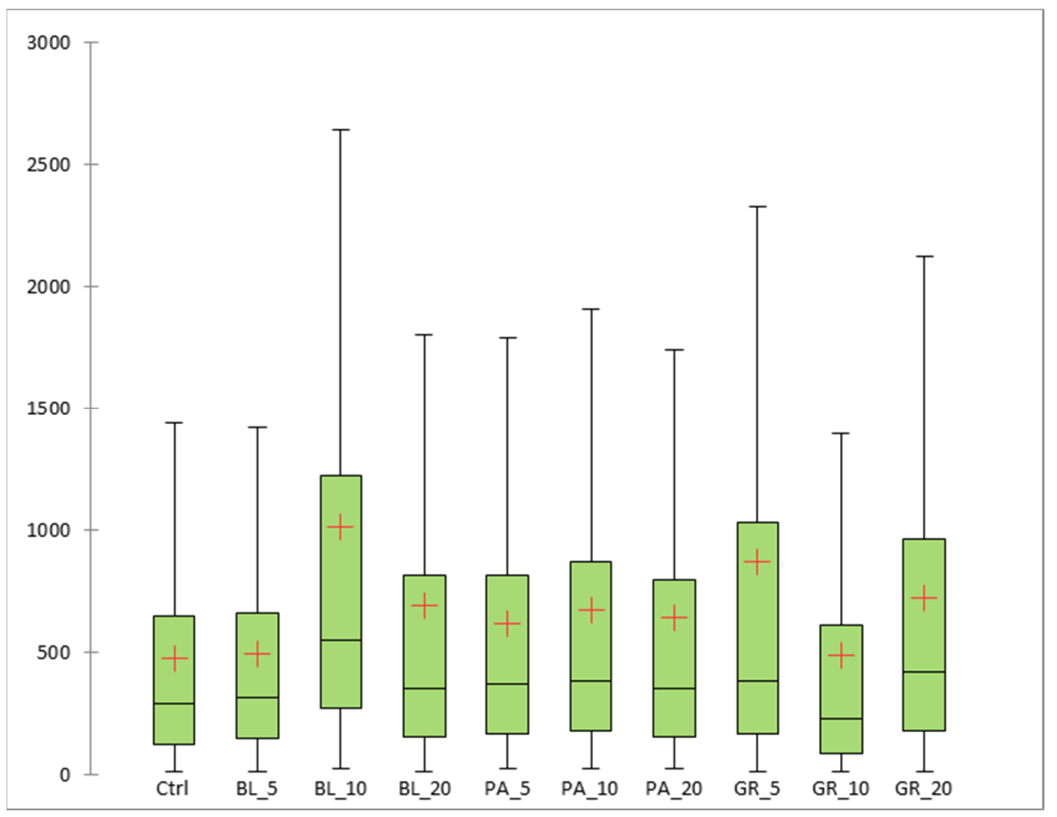

Figure 6. The results of SEM of edible coatings: the size of the cracks (fissure area) in the surface of the coatings $\left[\mathrm{nm}^{2}\right]$ (BL_5, edible coating with 5\% of blueberry extract; BL_10, edible coating with $10 \%$ of blueberry extract; BL_20, edible coating with $20 \%$ of blueberry extract; GR_5, edible coating with $5 \%$ of red grape extract; GR_10, edible coating with $10 \%$ of red grape extract; GR_20, edible coating with $20 \%$ of red grape extract; PA_5, edible coating with 5\% of parsley extract; PA_10, edible coating with $10 \%$ of parsley extract; PA_20, edible coating with $20 \%$ of parsley extract; Ctrl, control = edible coating without added extract).

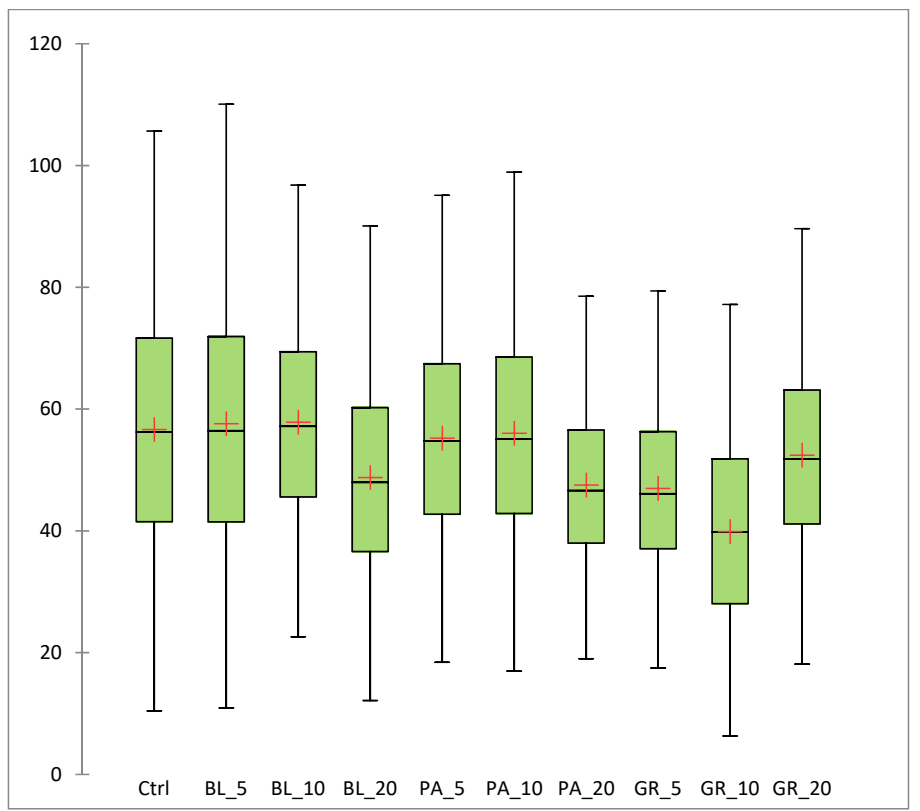

Figure 7. The results of SEM of edible coatings: the distance between cracks in the surface of the coatings (nm) (BL_5, edible coating with 5\% of blueberry extract; BL_10, edible coating with $10 \%$ of blueberry extract; BL_20, edible coating with $20 \%$ of blueberry extract; GR_5, edible coating with $5 \%$ of red grape extract; GR_10, edible coating with 10\% of red grape extract; GR_20, edible coating with $20 \%$ of red grape extract; PA_5, edible coating with 5\% of parsley extract; PA_10, edible coating with $10 \%$ of parsley extract; PA_20, edible coating with $20 \%$ of parsley extract; Ctrl, control = edible coating without added extract). 
An analysis of the surface of the formed gel demonstrated the existence of differences between the coatings. In this study, the total area of the cracks and their mutual distance were used to measure the change of the surface. The cracks formed in the control sample had the smallest area (474.32 $\mathrm{nm}^{2}$ on average). The largest crack areas were confirmed in samples BL_10 (1014.51 nm² on average) and GR_5 (868.22 $\mathrm{nm}^{2}$ on average). The smallest difference vs. the control was confirmed for samples BL_5 (494.33 $\mathrm{nm}^{2}$ on average), GR_10 (490.09 $\mathrm{nm}^{2}$ on average) and PA_5 (618.54 $\mathrm{nm}^{2}$ on average). A statistically significant difference $(p<0.05)$ in the area of cracks was documented between the control and all samples with added plant pomace. Our results did not confirm the effect of the addition of glycerol as a suitable plasticiser on the formation of the chitosan coating, as described by some authors $[62,63]$. This may be due to the smaller magnification $(1-5 \mathrm{~K})$ used in the mentioned studies. The formation of cracks was demonstrated in the samples analysed by us only at a magnification of $80 \mathrm{~K}$; the changes were insignificant at smaller magnifications. Improvement of the plasticising properties of the coating could be achieved by the addition of another plasticiser, such as vegetable mucilage [64].

The distance between the cracks has a direct correlation to the total area $\mathrm{R}=0.71$ $(p<0.05)$. The larger the area, the smaller the distance between the cracks. A linear dependence of the increasing concentration on the distance between cracks was not confirmed. A distance between cracks ( $56.66 \mathrm{~nm}$ on average) was found in the control sample, without any significant difference as compared with samples BL_5 (57.61 nm on average), PA_5 (55.24 $\mathrm{nm}$ on average) and PA_10 (56.03 $\mathrm{nm}$ on average) $(\mathrm{p}>0.05)$. In the other samples, a statistically significant difference $(p<0.05)$ vs. the control was observed in the distance between cracks.

Although the formation of cracks on the surface of the coating was proven at a magnification of $80 \mathrm{~K}$, the cracks did not significantly interfere with the profile of the coating material. The transverse refractive indices did not document any cracks going through the whole layer (Figure 5). This means that the protective function of the edible coating was not disrupted by the added plant pomace. Khorram et al. [47] confirmed the presence of fractures and uneven surface at the addition of 3.5\% Persian gum and 5\% gelatine at as low a magnification as 500. It is therefore possible to assume that, unlike the addition of polymers, such as Persian gum and gelatine, the addition of pomace does not result in a change in the integrity of the full width of the formed coating but only on its surface.

The obtained micrographs of the analysed coatings also showed the formation of an uneven surface during the handling of the samples (Figure 8). The information that the handling of the coating causes structural changes, manifested as the undulation of the surface, is an additional partial result of the study. A more suitable method for evaluation is the direct gel formation on the conductive target used in this study, which allows the assessment of the effect of the addition of pomace, rather than some accidental deformations caused during sample handling (transport, handling, refraction). 


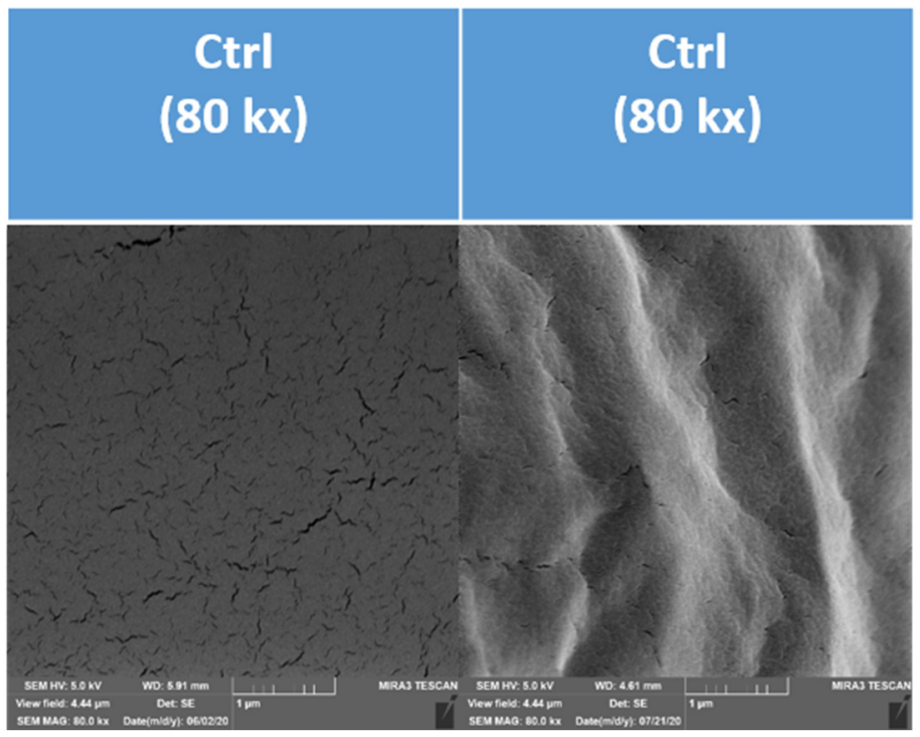

Figure 8. Effect of processing on the microscopic structure of the control sample of an edible coating. (the left picture) A coating formed on a strip. (the right picture) A coating formed outside a strip.

\subsection{Biodegradability of Plastics by a Mixed Culture}

Experiments with the biodegradability of bioplastics by a mixed culture have shown that all tested samples of bioplastics can serve as a substrate for a mixed culture of microorganisms. From the obtained values of biological oxygen demand (BOD) it is clear that the control sample, without the addition of pomace from plant materials, showed the highest BOD values (Figure 9, sample Ctrl). A lag phase, i.e., a period of 10 to $40 \mathrm{~h}$ necessary for adaptation of microorganisms after the addition of bioplastics, could be observed in all samples. The course of BOD was similar for all samples (except PA_5) for $60 \mathrm{~h}$. Afterwards, a different biodegradability of the tested bioplastics began to show.

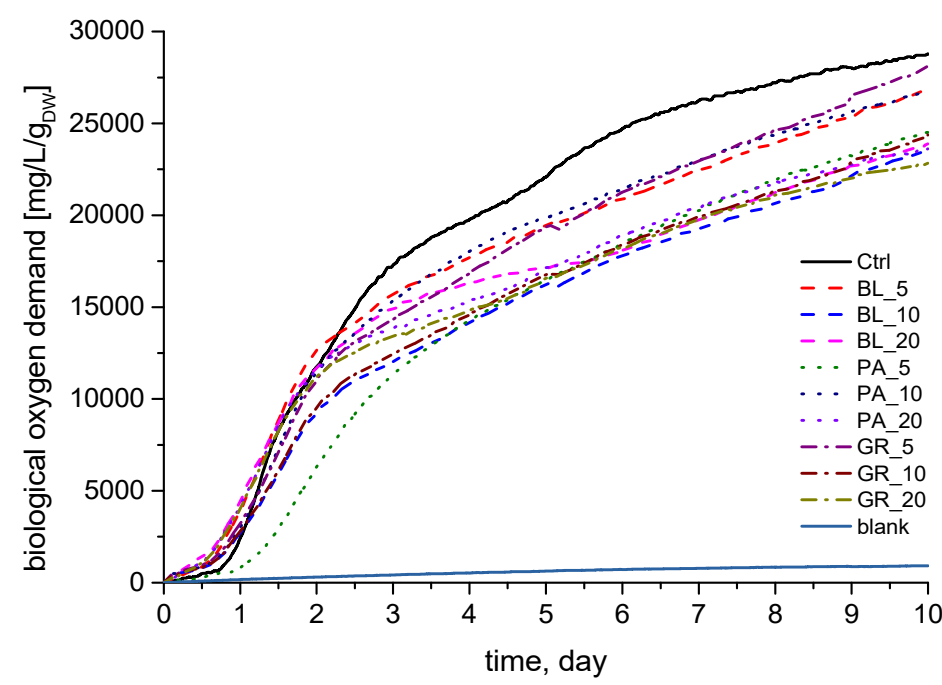

Figure 9. The course of respiratory activity of the tested biogas samples (the graph shows average values; $n=3)$.

Compared to the control, all samples achieved lower final BOD values. The first group of samples achieved BOD values that were lower by 6.8\% (BL_5), 7\% (PA_10) and 3\% (GR_5). The second group of samples achieved BOD values lower by $18 \%$ (BL_10), 17\% (BL_20), 15\% (PA_5), 18\% (PA_20), 15\% (GR_10) and 21\% (GR_20) as compared to the control. Thanks to the good solubility of chitosan in water and the weak intermolecular 
bonds between chitosan and the plant pomace, relatively high values of biodegradation of the prepared bioplastics can be achieved. This has also been confirmed by other authors who have performed experiments with the biodegradation of chitosan-based bioplastics and plant pomaces [65].

\section{Conclusions}

The study indicated the influence of the examined plant extracts on coatings' sensory properties, as well as on their barrier and biodegradability characteristics. The sensory quality of all edible coating samples analysed in our study was acceptable. In terms of overall pleasantness, the samples containing parsley pomace in all concentrations and a sample containing $5 \%$ grape pomace received the highest evaluations. As part of the evaluation of the probability of purchasing commodities in edible coating, the use of samples with $5 \%$ and $10 \%$ concentrations of parsley pomace was the most conceivable for the panellists. For all samples, the difference in colour from the control described by the $\Delta \mathrm{E} 2000$ parameter was recognisable to the human eye. The lowest values were obtained for the sample containing $5 \%$ parsley pomace, the highest for the sample with $20 \%$ blueberry pomace. It was shown that the addition of plant pomace did not lead to a disruption of the protective function of the experimentally prepared edible coatings and that these coatings achieved relatively high values of biodegradation. The study gave clear directions for possible applications for coatings on various food commodities, including commercial-scale application. Further studies aimed at monitoring the interactions between coatings and packed food commodities and also coatings' properties under different storage conditions and times need to be conducted.

Our study suggests that coatings with incorporated grape, blueberry and in particular, parsley pomace extracts have the potential to be used on a commercial scale.

Author Contributions: Conceptualization, methodology and software: A.T., D.D. and S.J.; validation: B.T., A.T. and D.D.; investigation: A.T., M.P., Z.J., D.D., M.V., T.V., S.J., K.T. and M.Z.; resources: B.T.; writing—original draft preparation: A.T., M.P., Z.J., M.V. and T.V.; writing—review and editing: A.T., D.D. and B.T.; supervision: B.T.; project administration: B.T. All authors have read and agreed to the published version of the manuscript.

Funding: This research was funded by the project FVHE/Tremlová/ITA2020 from the University of Veterinary Sciences Brno, Czech Republic.

Institutional Review Board Statement: Not applicable.

Informed Consent Statement: Not applicable.

Data Availability Statement: Not applicable.

Conflicts of Interest: The authors declare no conflict of interest. The funders had no role in the design of the study; in the collection, analyses, or interpretation of data; in the writing of the manuscript, or in the decision to publish the results.

\section{References}

1. Jafarzadeh, S.; Nafchi, A.M.; Salehabadi, A.; Oladzad-abbasabadi, N.; Jafari, S.M. Application of bio-nanocomposite films and edible coatings for extending the shelf life of fresh fruits and vegetables. Adv. Colloid Interface Sci. 2021, 291, 102405. [CrossRef] [PubMed]

2. Al-Tayyar, N.A.; Youssef, A.M.; Al-Hindi, R.R. Edible coatings and antimicrobial nanoemulsions for enhancing shelf life and reducing foodborne pathogens of fruits and vegetables: A review. Sustain. Mater. Technol. 2020, 26, e00215. [CrossRef]

3. Jancikova, S.; Dordevic, D.; Jamroz, E.; Behalova, H.; Tremlova, B. Chemical and physical characteristics of edible films, based on K-and l-carrageenans with the addition of lapacho tea extract. Foods 2020, 9, 357. [CrossRef] [PubMed]

4. Du, Y.; Yang, F.; Yu, H.; Cheng, Y.; Guo, Y.; Yao, W.; Xie, Y. Fabrication of novel self-healing edible coating for fruits preservation and its performance maintenance mechanism. Food Chem. 2021, 351, 129284. [CrossRef]

5. Ezazi, A.; Javadi, A.; Jafarizadeh-Malmiri, H.; Mirzaei, H. Development of a chitosan-propolis extract edible coating formulation based on physico-chemical attributes of hens' eggs: Optimization and characteristics edible coating of egg using chitosan and propolis. Food Biosci. 2021, 40, 100894. [CrossRef] 
6. Tavares, L.; Souza, H.K.; Gonçalves, M.P.; Rocha, C.M. Physicochemical and microstructural properties of composite edible film obtained by complex coacervation between chitosan and whey protein isolate. Food Hydrocoll. 2021, 113, 106471. [CrossRef]

7. Quintana, S.E.; Llalla, O.; García-Risco, M.R.; Fornari, T. Comparison between essential oils and supercritical extracts into chitosan-based edible coatings on strawberry quality during cold storage. J. Supercrit. Fluids 2021, 171, 105198. [CrossRef]

8. Santagata, G.; Mallardo, S.; Fasulo, G.; Lavermicocca, P.; Valerio, F.; Di Biase, M.; Di Stasio, M.; Malinconico, M.; Volpe, M.G. Pectin-honey coating as novel dehydrating bioactive agent for cut fruit: Enhancement of the functional properties of coated dried fruits. Food Chem. 2018, 258, 104-110. [CrossRef]

9. Xiong, Y.; Kamboj, M.; Ajlouni, S.; Fang, Z. Incorporation of salmon bone gelatine with chitosan, gallic acid and clove oil as edible coating for the cold storage of fresh salmon fillet. Food Control 2021, 125, 107994. [CrossRef]

10. Hellebois, T.; Tsevdou, M.; Soukoulis, C. Functionalizing and bio-preserving processed food products via probiotic and synbiotic edible films and coatings. In Probiotic and Prebiotics in Foods: Challenges, Innovations and Advances; da Cruz, A.G., Schwinden Prudencio, E., Almeida Esmerino, E., da Silva, M.C., Eds.; Academic Press: London, UK, 2020; Volume 94, pp. 161-221.

11. Kõrge, K.; Bajić, M.; Likozar, B.; Novak, U. Active chitosan-chestnut extract films used for packaging and storage of fresh pasta. Int. J. Food Sci. Technol. 2020, 55, 3043-3052. [CrossRef]

12. Jiang, B.; Wang, L.; Zhu, M.; Wu, S.; Wang, X.; Li, D.; Tian, B. Separation, structural characteristics and biological activity of lactic acid bacteria exopolysaccharides separated by aqueous two-phase system. LWT 2021, 147, 111617. [CrossRef]

13. Jiang, B.; Wang, X.; Wang, L.; Wu, S.; Li, D.; Liu, C.; Feng, Z. Fabrication and characterization of a microemulsion stabilized by integrated phosvitin and gallic acid. J. Agric. Food Chem. 2020, 68, 5437-5447. [CrossRef]

14. Mileriene, J.; Serniene, L.; Henriques, M.; Gomes, D.; Pereira, C.; Kondrotiene, K.; Kasetiene, N.; Lauciene, L.; Sekmokiene, D.; Malakauskas, M. Effect of liquid whey protein concentrate-based edible coating enriched with cinnamon carbon dioxide extract on the quality and shelf life of Eastern European curd cheese. J. Dairy Sci. 2021, 104, 1504-1517. [CrossRef]

15. Torres-León, C.; Vicente, A.A.; Flores-López, M.L.; Rojas, R.; Serna-Cock, L.; Alvarez-Pérez, O.B.; Aguilar, C.N. Edible films and coatings based on mango (var. Ataulfo) by-products to improve gas transfer rate of peach. LWT 2018, 97, 624-631. [CrossRef]

16. Suhag, R.; Kumar, N.; Petkoska, A.T.; Upadhyay, A. Film formation and deposition methods of edible coating on food products: A review. Food Res. Int. 2020, 136, 109582. [CrossRef]

17. Alfei, S.; Marengo, B.; Zuccari, G. Nanotechnology application in food packaging: A plethora of opportunities versus pending risks assessment and public concerns. Food Res. Int. 2020, 137, 109664. [CrossRef]

18. Wang, Q.; Liu, W.; Tian, B.; Li, D.; Liu, C.; Jiang, B.; Feng, Z. Preparation and characterization of coating based on protein nanofibers and polyphenol and application for salted duck egg yolks. Foods 2020, 9, 449. [CrossRef]

19. Cheba, B.A. Chitosan: Properties, Modifications and Food Nanobiotechnology. Procedia Manuf. 2020, 46, 652-658. [CrossRef]

20. Fortunati, E. Chapter 38-Multifunctional Films, Blends, and Nanocomposites Based on Chitosan: Use in Antimicrobial Packaging. In Antimicrobial Food Packaging; Academic Press: London, UK, 2016; pp. 467-477. [CrossRef]

21. Jiang, H.; Sun, Z.; Jia, R.; Wang, X.; Huang, J. Effect of Chitosan as an Antifungal and Preservative Agent on Postharvest Blueberry. J. Food Qual. 2016, 39, 516-523. [CrossRef]

22. Nair, M.S.; Saxena, A.; Kaur, C. Effect of chitosan and alginate based coatings enriched with pomegranate peel extract to extend the postharvest quality of guava (Psidium guajava L.). Food Chem. 2018, 240, 245-252. [CrossRef]

23. Silva, G.M.; Silva, W.B.; Medeiros, D.B.; Salvador, A.R.; Cordeiro, M.H.; da Silva, N.M.; Santana, D.B.; Mizobutsi, G.P. The chitosan affects severely the carbon metabolism in mango (Mangifera indica L. cv. Palmer) fruit during storage. Food Chem. 2017, 237, 372-378. [CrossRef]

24. Awad, M.A.; Al-Qurashi, A.D.; Mohamed, S.A.; El-Shishtawy, R.M. Quality and biochemical changes of 'Hindi-Besennara'mangoes during shelf life as affected by chitosan, gallic acid and chitosan gallate. J. Food Sci. Technol. 2017, 54, 4139-4148. [CrossRef] [PubMed]

25. Jongsri, P.; Rojsitthisak, P.; Wangsomboondee, T.; Seraypheap, K. Influence of chitosan coating combined with spermidine on anthracnose disease and qualities of 'Nam Dok Mai'mango after harvest. Sci. Hortic. 2017, 224, 180-187. [CrossRef]

26. Drevinskas, T.; Naujokaitytè, G.; Maruška, A.; Kaya, M.; Sargin, I.; Daubaras, R.; Česonienė, L. Effect of molecular weight of chitosan on the shelf life and other quality parameters of three different cultivars of Actinidia kolomikta (kiwifruit). Carbohydr. Polym. 2017, 173, 269-275. [CrossRef] [PubMed]

27. Liu, X.; Tang, C.; Han, W.; Xuan, H.; Ren, J.; Zhang, J.; Ge, L. Characterization and preservation effect of polyelectrolyte multilayer coating fabricated by carboxymethyl cellulose and chitosan. Colloids Surf. A Physicochem. Eng. Asp. 2017, 529, 1016-1023. [CrossRef]

28. Deng, Z.; Jung, J.; Simonsen, J.; Wang, Y.; Zhao, Y. Cellulose nanocrystal reinforced chitosan coatings for improving the storability of postharvest pears under both ambient and cold storages. J. Food Sci. 2017, 82, 453-462. [CrossRef]

29. Prior, R.L.; Cao, G.; Martin, A.; Sofic, E.; McEwen, J.; O’Brien, C.; Lischner, N.; Ehlenfeldt, M.; Kalt, W.; Krewer, G.; et al. Antioxidant capacity as influenced by total phenolic and anthocyanin content, maturity, and variety of Vaccinium species. J. Agric. Food Chem. 1998, 46, 2686-2693. [CrossRef]

30. Pertuzatti, P.B.; Barcia, M.T.; Gómez-Alonso, S.; Godoy, H.T.; Hermosin-Gutierrez, I. Phenolics profiling by HPLC-DAD-ESI-MSn aided by principal component analysis to classify Rabbiteye and Highbush blueberries. Food Chem. 2021, 340, 127958. [CrossRef] 
31. Zhang, L.; Li, X.; Pang, Y.; Cai, X.; Lu, J.; Ren, X.; Kong, Q. Phenolics composition and contents, as the key quality parameters of table grapes, may be influenced obviously and differently in response to short-term high temperature. LWT 2021, $149,111791$. [CrossRef]

32. Sirohi, R.; Tarafdar, A.; Singh, S.; Negi, T.; Gaur, V.K.; Gnansounou, E.; Bhartiraja, B. Green processing and biotechnological potential of grape pomace: Current trends and opportunities for sustainable biorefinery. Bioresour. Technol. 2020, 314, 123771. [CrossRef]

33. Poni, S.; Gatti, M.; Palliotti, A.; Dai, Z.; Duchêne, E.; Truong, T.T.; Ferrarae, G.; Matarrese, A.M.S.; Gallotta, A.; Bellincontro, A.; et al. Grapevine quality: A multiple choice issue. Sci. Hortic. 2018, 234, 445-462. [CrossRef]

34. El-Zaeddi, H.; Calín-Sánchez, Á.; Nowicka, P.; Martínez-Tomé, J.; Noguera-Artiaga, L.; Burló, F.; Wojdyło, A.; CarbonellBarrachina, Á. Preharvest treatments with malic, oxalic, and acetylsalicylic acids affect the phenolic composition and antioxidant capacity of coriander, dill and parsley. Food Chem. 2017, 226, 179-186. [CrossRef]

35. Farzaei, M.H.; Abbasabadi, Z.; Ardekani, M.R.S.; Rahimi, R.; Farzaei, F. Parsley: A review of ethnopharmacology, phytochemistry and biological activities. J. Tradit. Chin. Med. 2013, 33, 815-826. [CrossRef]

36. Jancikova, S.; Jamróz, E.; Kulawik, P.; Tkaczewska, J.; Dordevic, D. Furcellaran/gelatin hydrolysate/rosemary extract composite films as active and intelligent packaging materials. Int. J. Biol. Macromol. 2019, 131, 19-28. [CrossRef]

37. Rodríguez, G.M.; Sibaja, J.C.; Espitia, P.J.P.; Otoni, C.G. Antioxidant active packaging based on papaya edible films incorporated with Moringa oleifera and ascorbic acid for food preservation. Food Hydrocoll. 2020, 103, 105630. [CrossRef]

38. Alizadeh Behbahani, B.; Noshad, M.; Jooyandeh, H. Improving oxidative and microbial stability of beef using Shahri Balangu seed mucilage loaded with Cumin essential oil as a bioactive edible coating. Biocatal. Agric. Biotechnol. 2020, 24, 101563. [CrossRef]

39. Balti, R.; Ben Mansour, M.; Zayoud, N.; Le Balc'h, R.; Brodu, N.; Arhaliass, A.; Massé, A. Active exopolysaccharides based edible coatings enriched with red seaweed (Gracilaria gracilis) extract to improve shrimp preservation during refrigerated storage. Food Biosci. 2020, 34, 100522. [CrossRef]

40. Ozdemir, M.; Floros, J.D. Optimization of edible whey protein films containing preservatives for water vapor permeability, water solubility and sensory characteristics. J. Food Eng. 2008, 86, 215-224. [CrossRef]

41. Kim, S.J.; Ustunol, Z. Sensory Attributes of Whey Protein Isolate and Candelilla Wax Emulsion Edible Films. J. Food Sci. 2001, 66, 909-911. [CrossRef]

42. Jancikova, S.; Dordevic, D.; Javurkova, Z. Effect of gelling agents on colour characteristics of fruit jams. Iraqi J. Agric. Sci. 2019, 50, 675-688.

43. Luo, M.R.; Cui, G.; Rigg, B. The development of the CIE 2000 colour-difference formula: CIEDE2000. Colour Res. Appl. 2001, 26, 340-350. [CrossRef]

44. Sharma, G. Colour fundamentals for digital imaging. In Digital Colour Imaging Handbook; Sharma, G., Ed.; CRC Press: Boca Raton, FL, USA, 2003; pp. 1-114.

45. Zifkin, M.; Jin, A.; Ozga, J.A.; Zaharia, I.L.; Schernthaner, J.P.; Gesell, A.; Abrams, S.R.; Kennedy, J.A.; Constabel, C.P. Gene Expression and Metabolite Profiling of Developing Highbush Blueberry Fruit Indicates Transcriptional Regulation of Flavonoid Metabolism and Activation of Abscisic Acid Metabolism. Plant Physiol. 2012, 158, 200-224. [CrossRef] [PubMed]

46. Wu, Y.; Zhang, W.; Yu, W.; Zhao, L.; Song, S.; Xu, W.; Zhang, C.; Ma, C.; Wang, L.; Wang, S. Study on the volatile composition of table grapes of three aroma types. LWT 2019, 115, 108450. [CrossRef]

47. Khorram, F.; Ramezanian, A.; Hosseini, S.M.H. Shellac, gelatin and Persian gum as alternative coating for orange fruit. Sci. Hortic. 2017, 225, 22-28. [CrossRef]

48. Mantilla, N.; Castell-Perez, M.E.; Gomes, C.; Moreira, R.G. Multilayered antimicrobial edible coating and its effect on quality and shelf-life of fresh-cut pineapple (Ananas comosus). LWT_Food Sci. Technol. 2013, 51, 37-43. [CrossRef]

49. Zhao, Y.; McDaniel, M. Sensory quality of foods associated with edible film and coating systems and shelf-life extension. In Innovations in Food Packaging; Han, J.H., Ed.; Academic Press: London, UK, 2005; pp. 434-453. ISBN 9780123116321. [CrossRef]

50. Hansen, L.T.; Gill, T.; Hussa, H.H. Effects of salt and storage temperature on chemical, microbiological and sensory changes in cold-smoked salmon. Food Res. Int. 1995, 28, 123-130. [CrossRef]

51. Gutiérrez, T.J.; Álvarez, K. Physico-chemical properties and in vitro digestibility of edible films made from plantain flour with added Aloe vera gel. J. Funct. Foods 2016, 26, 750-762. [CrossRef]

52. Jiménez-Aguilar, D.M.; Ortega-Regules, A.E.; Lozada-Ramírez, J.D.; Pérez-Pérez, M.C.I.; Vernon-Carter, E.J.; Welti-Chanes, J. Colour and chemical stability of spray-dried blueberry extract using mesquite gum as wall material. J. Food Compos. Anal. 2011, 24, 889-894. [CrossRef]

53. Khoo, H.E.; Azlan, A.; Tang, S.T.; Lim, S.M. Anthocyanidins and anthocyanins: Coloured pigments as food, pharmaceutical ingredients, and the potential health benefits. Food Nutr. Res. 2017, 61, 1361779. [CrossRef] [PubMed]

54. Karača, S.; Trifković, K.; Bušić, A.; Đorđević, V.; Belščak-Cvitanović, A.; Vojvodić Cebin, A.; Bugarski, B.; Komes, D. The functional potential of immortelle (Helichrysum italicum) based edible films reinforced with proteins and hydrogel particles. LWT 2019, 99, 387-395. [CrossRef]

55. Poureini, F.; Mohammadi, M.; Najafpour, G.D.; Nikzad, M. Comparative study on the extraction of apigenin from parsley leaves (Petroselinum crispum L.) by ultrasonic and microwave methods. Chem. Pap. 2020, 74, 3857-3871. [CrossRef]

56. Cosme, F.; Pinto, T.; Vilela, A. Phenolic compounds and antioxidant activity in grape juices: A chemical and sensory view. Beverages 2018, 4, 22. [CrossRef] 
57. Mazza, G.; Fukumoto, L.; Delaquis, P.; Girard, B.; Ewert, B. Anthocyanins, phenolics, and colour of Cabernet franc, Merlot, and Pinot noir wines from British Columbia. J. Agric. Food Chem. 1999, 47, 4009-4017. [CrossRef] [PubMed]

58. Burin, V.M.; Falcão, L.D.; Gonzaga, L.V.; Fett, R.; Rosier, J.P.; Bordignon-Luiz, M.T. Colour, phenolic content and antioxidant activity of grape juice. Food Sci. Technol. 2010, 30, 1027-1032. [CrossRef]

59. Navarro, R.; Arancibia, C.; Herrera, M.L.; Matiacevich, S. Effect of type of encapsulating agent on physical properties of edible films based on alginate and thyme oil. Food Bioprod. Process. 2016, 97, 63-75. [CrossRef]

60. Veiga-Santos, P.; Silva, L.T.; de Souza, C.O.; da Silva, J.R.; Albuquerque, E.C.; Druzian, J.I. Coffee-cocoa additives for bio-based antioxidant packaging. Food Packag. Shelf Life 2018, 18, 37-41. [CrossRef]

61. Benítez, S.; Achaerandio, I.; Pujolà, M.; Sepulcre, F. Aloe vera as an alternative to traditional edible coatings used in fresh-cut fruits: A case of study with kiwifruit slices. LWT-Food Sci. Technol. 2015, 61, 184-193. [CrossRef]

62. Jouki, M.; Khazaei, N.; Ghasemlou, M.; Hadinezhad, M. Effect of glycerol concentration on edible film production from cress seed carbohydrate gum. Carbohydr. Polym. 2013, 96, 39-46. [CrossRef]

63. Khazaei, N.; Esmaiili, M.; Djomeh, Z.E.; Ghasemlou, M.; Jouki, M. Characterization of new biodegradable edible film made from basil seed (Ocimum basilicum L.) gum. Carbohydr. Polym. 2014, 102, 199-206. [CrossRef]

64. Beikzadeh, S.; Khezerlou, A.; Jafari, S.M.; Pilevar, Z.; Mortazavian, A.M. Seed mucilages as the functional ingredients for biodegradable films and edible coatings in the food industry. Adv. Colloid Interface Sci. 2020, 280, 102164. [CrossRef]

65. Kaya, M.; Khadem, S.; Cakmak, Y.S.; Mujtaba, M.; Ilk, S.; Akyuz, L.; Salaberria, A.M.; Labidi, J.; Abdulqadir, A.H.; Deligöz, E. Antioxidative and antimicrobial edible chitosan films blended with stem, leaf and seed extracts of Pistacia terebinthus for active food packaging. RSC Adv. 2018, 8, 3941-3950. [CrossRef] 